\title{
Wind Energy Facilities and Residential Properties: The Effect of Proximity and View on Sales Prices*
}

\author{
Ben Hoen \\ Ernest Orlando Lawrence Berkeley National Laboratory \\ c/o 20 Sawmill Road, Milan, NY 12571 845-758-1896 benhoen2@earthlink.net \\ Ryan Wiser \\ Ernest Orlando Lawrence Berkeley National Laboratory \\ 1 Cyclotron Road, Mailstop 90R4000, Berkeley, CA 94720 510-486-5474 rhwiser@lbl.gov \\ Peter Cappers \\ Ernest Orlando Lawrence Berkeley National Laboratory \\ c/o 7847 Karakul Lane, Fayetteville, NY 13066 315-637-0513 pacappers@lbl.gov \\ Mark Thayer \\ San Diego State University \\ 307 Nasatir Hall, San Diego, CA 92182 619-594-5510 mthayer@mail.sdsu.edu \\ Gautam Sethi \\ Bard Center for Environmental Policy at Bard College \\ 30 Campus Road, Annandale-on-Hudson, NY 12504-5000845-758-7386 sethi@bard.edu
}

April 2010

\footnotetext{
The work described in this paper was funded by the Office of Energy Efficiency and Renewable Energy (Wind \& Hydropower Technologies Program) of the U.S. Department of Energy under Contract No. DE-AC02-05CH1123.
} 


\section{Abstract}

With an increasing number of communities considering nearby wind power developments, there is a need to empirically investigate community concerns about wind project development. One such concern is that property values may be adversely affected by wind energy facilities, and relatively little research exists on the subject. The present research investigates roughly 7,500 sales of single-family homes surrounding 24 existing U.S. wind facilities. Across four different hedonic models the results are consistent: neither the view of the wind facilities nor the distance of the home to those facilities is found to have a statistically significant effect on home sales prices.

\section{Introduction}

Wind power development has expanded dramatically in recent years (GWEC, 2009) and that expansion is expected to continue (GWEC, 2008; Wiser and Hand, 2010). The U.S. Department of Energy, for example, published a report that analyzed the feasibility of meeting $20 \%$ of U.S. electricity demand with wind energy by 2030 (US DOE, 2008).

To meet a 20\% wind electricity target in the United States, roughly 3,000 wind facilities would need to be sited, permitted, and constructed. ${ }^{1}$ Though surveys show that public acceptance is

\footnotetext{
${ }^{1}$ The average size of wind power projects built in the U.S. in 2007 and 2008 was approximately 100 MW (Wiser and Bolinger, 2009) and the total amount of capacity required to reach $20 \%$ wind electricity is roughly 300,000 MW (US DOE, 2008). Therefore, to achieve $20 \%$ wind electricity by 2030, a total of 3,000 wind facilities may need to be sited and permitted; by the end of 2009, installed wind power capacity in the U.S. stood at 35,000 MW.
} 
high in general for wind energy (e.g., Wolsink, 2000; Firestone and Kempton, 2006), a variety of local concerns exist that can impact the length and outcome of the siting and permitting process. One such concern is related to the views of and proximity to wind facilities and how these might impact surrounding property values. To that end, surveys of local communities considering wind facilities have frequently ranked adverse impacts on aesthetics and property values in the top tier of concerns relative to other matters such as impacts on wildlife habitat and mortality, radar and communications systems, ground transportation, and historic and cultural resources (e.g., BBC R\&C, 2005; Firestone and Kempton, 2006).

Concerns about the possible impacts of wind projects on residential property values can be categorized into three potential effects:

- Area stigma: A perception that the general area surrounding a wind energy facility will appear more developed, which may adversely affect home values in the local community regardless of whether any individual home has a view of the wind turbines.

- Scenic vista stigma: A perception that a home may be devalued because of the view of a wind energy facility, and the potential impact of that view on an otherwise scenic vista.

- Nuisance stigma: A perception that factors that may occur in close proximity to wind turbines, such as sound and shadow flicker, will have an adverse influence on home values.

Any combination of these three potential stigmas might affect a particular home. Consequently, each of the three potential impacts must be considered when analyzing the effects of wind facilities on residential sales prices. 
This paper uses several hedonic pricing models to analyze a sample of 7,459 arms-length residential transactions occurring between 1996 and 2007 for homes located near 24 existing wind facilities spread across nine U.S. states. In so doing, the paper investigates the degree to which views of and proximity to wind facilities affect sales prices.

The remainder of the paper is organized as follows. The next section contains a summary of the existing literature that has investigated the effects of wind energy on residential property values. Then the data used in the present analysis is described. Following that, a set of four hedonic models are estimated to test for the existence property value impacts associated with the wind energy facilities. Then the findings regarding the existence and magnitude of the three stigmas mentioned above are described. The paper ends with a brief discussion of future research possibilities.

\section{Previous Research}

Much of the existing literature investigating the potential property value effects from wind facilities has significant limitations that restrict one's ability to draw strong conclusions on the nature, existence, and magnitude of such effects. Nonetheless, a brief review of the existing literature sets the stage for and motivates the later discussion of the methods and results of the present work.

In one of the most recent studies, Sims et al. (2008) applied a hedonic model to investigate scenic vista and nuisance stigmas using 199 residential transactions within $1 / 4$ of a mile of the 16turbine Bears Down wind facility in Cornwall, UK. They found no observed relationship between the number of wind turbines visible and a reduction in house value, nor did they find 
significant evidence to suggest a relationship between distance to the wind farm and house price. Sims and Dent (2007) used a hedonic model to investigate nuisance stigma and scenic vista stigma with 919 transactions for homes within five miles of two wind facilities in the UK, finding only limited evidence of a relationship between proximity to and views of turbines and sales prices, which local real estate experts attributed to other causes. Hoen (2006) investigated scenic vista stigma using a hedonic model to analyze 280 residential transactions occurring near a wind facility in Madison County, NY, and found no evidence that views of turbines significantly affect prices. Jordal-Jorgensen (1996) investigated nuisance stigma in Denmark, and found an adverse effect for homes located "close” to the turbines, but no statistical significance was reported. $^{2}$

Using different and somewhat simpler statistical methods, Poletti (2005; 2007) used a $t$-Test to investigate nuisance and area stigma by comparing the mean sales prices of 187 and 256 homes in Illinois and Wisconsin, respectively, located near wind facilities (target group) to those further away (control group). ${ }^{3}$ He divided these target and control groups into respective smaller and more-homogenous sub-groups, such as large and small tracts, and with and without homes, and found no statistical evidence that homes near the wind facilities sold for different prices than those farther away. Sterzinger et al. (2003) analyzed roughly 24,000 residential transactions, divided between those within five miles of a wind facility and those outside of five miles in an effort to assess area stigma. They compared residential appreciation rates over time, and found

\footnotetext{
${ }^{2}$ No definition was given for "close" in the paper.

${ }^{3}$ The 2007 study used the data contained in the 2005 study in combination with new data consisting of transactions that occurred in the interim period.
} 
no apparent difference between those homes within and outside of five miles from a wind facility, but the statistical significance of this comparison was not reported.

Other authors have used smaller samples of residential transactions and a variety of simple analytic techniques, without reporting statistical significance, and have found a lack of evidence of effects from nuisance stigma (Jerabek, 2001; Jerabek, 2002; Beck, 2004) and area stigma (DeLacy, 2005; Goldman, 2006). These results, however, are somewhat contrary to what one appraiser has found. In his investigation of nuisance stigma around a wind facility in Lee County, IL, McCann (2008) found that homes had lengthy selling periods that, he believes, also adversely affected transaction prices. Additionally, Kielisch (2009) investigated nuisance stigma by comparing twelve transactions of undeveloped land near two wind facilities in Wisconsin (Blue Sky Green Field and Forward) to undeveloped land transactions farther away. He found that land tracts near the wind facilities sold for dramatically lower prices than the comparable group, but the statistical significance of the comparison was not reported.

In addition to these revealed preference studies, a number of stated preference surveys (e.g., contingent valuation) have investigated the existence of potential effects. A survey of local residents, conducted after the wind facilities were erected, found no evidence of area stigma (Goldman, 2006), while another found limited evidence of these stigmas (Bond, 2008). Similarly, surveys of real estate experts conducted after facility construction have found no evidence of area or nuisance stigmas (Grover, 2002; Goldman, 2006). These results, however, are contrary to the expectations for area, scenic vista, and nuisance stigma effects predicted by 
local residents (Haughton et al., 2004; Firestone et al., 2007) and real estate experts (Haughton et al., 2004; Khatri, 2004; Kielisch, 2009) prior to wind facility construction. ${ }^{4}$

When this literature is looked at as a whole, it appears as if wind projects have been predicted to negatively impact residential property values when pre-construction surveys are conducted, but that statistically significant negative impacts have largely failed to materialize post-construction when actual transaction data become available for analysis. The studies that have investigated area stigma with market data have failed to uncover any significant effect. Of the studies focused on scenic vista and nuisance stigmas, only one is known to have found statistically significant adverse effects, yet the authors contend that those effects are likely driven by variables omitted from their analysis (Sims and Dent, 2007). Other studies that have relied on market data have sometimes found the possibility of negative effects, but the statistical significance of those results has rarely been reported.

Despite these findings, the existing literature leaves much to be desired. First, many studies have relied on surveys of homeowners or real estate professionals, rather than trying to quantify impacts based on market data. Second, a number of studies conducted rather simplified analyses of the underlying data, potentially not controlling for the many drivers of residential sales prices. Third, many of the studies have relied upon a very limited number of residential sales transactions, and therefore may not have had an adequate sample to statistically discern any property value effects, even if effects did exist. Fourth, and perhaps as a result, many of the

\footnotetext{
${ }^{4}$ It should be noted that the samples used by both Khatri (2004) and Kielisch (2009) contained a subset of respondents who did have some familiarity with valuing homes near wind facilities.
} 
studies did not conduct, or at least have not published, the statistical significance of their results. Fifth, when analyzed, there has been some emphasis on area stigma, and none of the studies has investigated all three possible stigmas simultaneously. Sixth, only a few of the studies (Hoen, 2006; Sims and Dent, 2007; Sims et al., 2008; Kielisch, 2009) conducted field visits to the homes to assess the quality of the scenic vista from the home, and the degree to which the wind facility might impact that scenic vista. Finally, with two exceptions (Sims and Dent, 2007; Sims et al., 2008), none of the studies were peer-reviewed.

\section{Data Overview}

The methods applied in the present work are intended to overcome many of the limitations of the existing literature. First, a large amount of data is collected from residential transactions within ten miles of 24 different wind projects in the U.S., allowing for a robust statistical analysis across a pooled dataset that includes a diverse group of wind project sites. Second, all three potential stigmas are investigated by exploring the potential impact of wind projects on home values based both on the distance to and view of the projects from the homes. Third, field visits were made to every home in the sample, allowing for a reliable assessment of the scenic vista enjoyed by each home and the degree to which the wind facility can be seen from the home, and to collect other value-influencing data from the field (e.g., if the home is situated on a cul-de-sac). Finally, a number of hedonic regression models are applied to the resulting dataset in order to assess the robustness of the results.

The 24 wind facilities included in the present sample (see Figure 1 and Table 1 ) were chosen from a set of 241 wind projects in the U.S. with a nameplate capacity greater than 0.6 megawatts 
(MW) and that completed construction in 2005 or before. ${ }^{5}$ The resulting 24 facilities were assigned to ten distinct study areas, and were selected based on: (1) the number of residential transactions both before and, more importantly, after wind facility construction, and especially in close proximity (e.g., within 2 miles) to the facility; (2) having comprehensive data on home characteristics, sales prices, and locations that were readily available in electronic form; and (3) being representative of the types of wind power projects being installed in the United States.

\section{Figure 1: Map of Study Areas and Potential Study Areas}

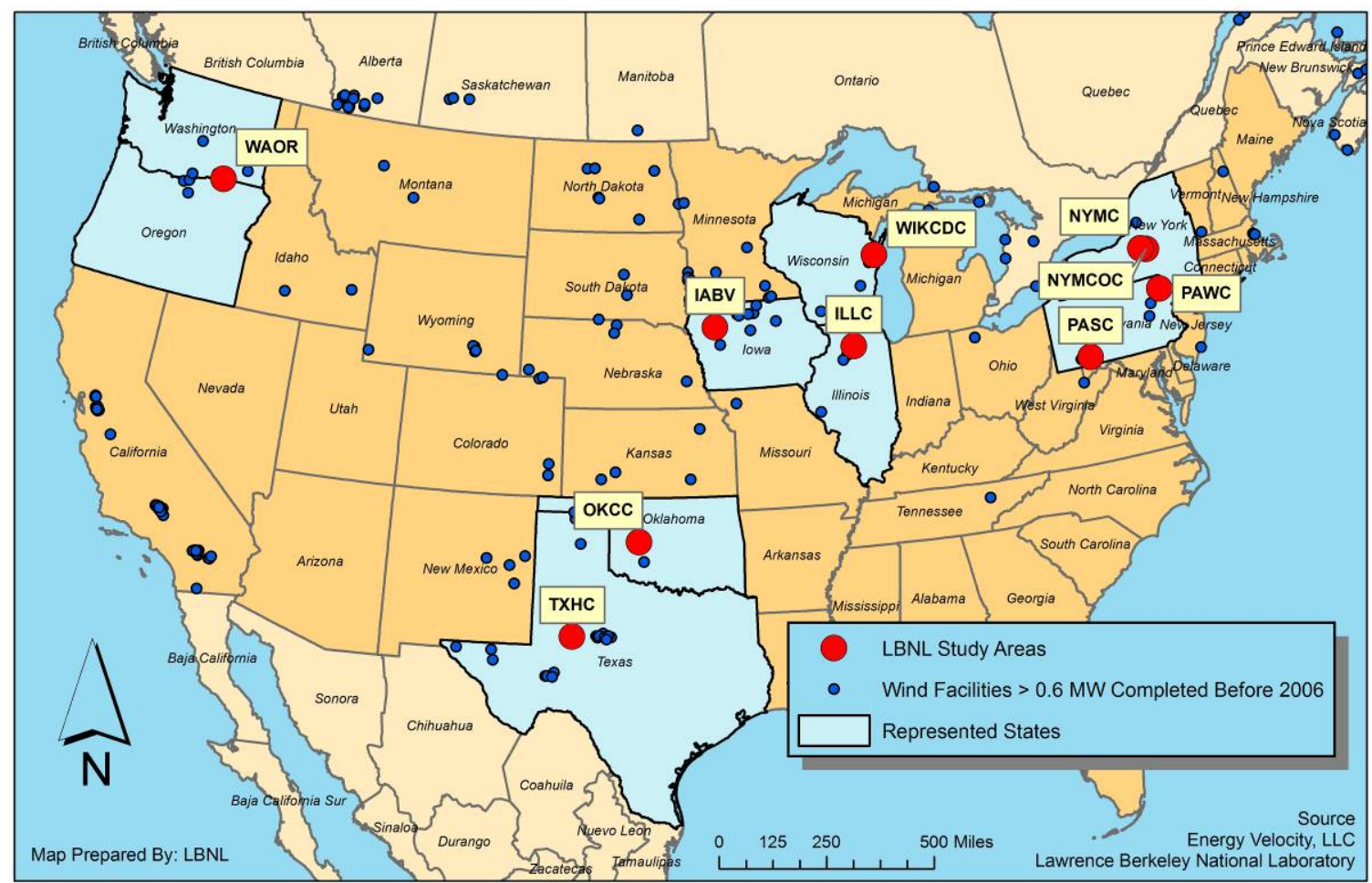

\footnotetext{
${ }^{5}$ The global data set was obtained from Energy Velocity, LLC. Energy Velocity LLC was owned at the time by Global Energy Decisions, which was later purchased by Ventyx. The dataset is available as Velocity Suite 2008 from Ventyx.
} 
Table 1: Summary of Study Areas

\begin{tabular}{|c|c|c|c|c|c|}
\hline $\begin{array}{l}\text { Study Area } \\
\text { Code }\end{array}$ & Study Area Counties, States & Facility Names & $\begin{array}{l}\text { Number } \\
\text { of } \\
\text { Turbines }\end{array}$ & $\begin{array}{l}\text { Number } \\
\text { of MW }\end{array}$ & $\begin{array}{c}\text { Max Hub } \\
\text { Height } \\
\text { (meters) }\end{array}$ \\
\hline WAOR & $\begin{array}{l}\text { Benton and Walla Walla Counties, } \\
\text { WA and Umatilla County, OR }\end{array}$ & $\begin{array}{l}\text { Vansycle Ridge, Stateline, } \\
\text { Nine Canyon I \& II, } \\
\text { Combine Hills }\end{array}$ & 582 & 429 & 60 \\
\hline TXHC & Howard County, TX & Big Spring I \& II & 46 & 34 & 80 \\
\hline OKCC & Custer County, OK & Weatherford I \& II & 98 & 147 & 80 \\
\hline IABV & Buena Vista County, IA & $\begin{array}{l}\text { Storm Lake I \& II, } \\
\text { Waverly, Intrepid I \& II }\end{array}$ & 381 & 370 & 65 \\
\hline ILLC & Lee County, IL & Mendota Hills, GSG Wind & 103 & 130 & 78 \\
\hline WIKCDC & Kewaunee and Door Counties, WI & Red River, Lincoln & 31 & 20 & 65 \\
\hline PASC & Somerset County, PA & $\begin{array}{l}\text { Green Mountain, Somerset, } \\
\text { Meyersdale }\end{array}$ & 34 & 49 & 80 \\
\hline PAWC & Wayne County, PA & Waymart & 43 & 65 & 65 \\
\hline NYMCOC & Madison and Oneida Counties, NY & Madison & 7 & 12 & 67 \\
\hline \multirow[t]{2}{*}{ NYMC } & Madison County, NY & Fenner & 20 & 30 & 66 \\
\hline & & TOTAL & 1,345 & 1,286 & \\
\hline
\end{tabular}

The ten study areas are located in nine separate states, and include projects in the Pacific Northwest, upper Midwest, the Northeast, and the South Central region. The wind projects included in the sample total 1,286 MW, or roughly 13\% of total U.S. wind power capacity installed at the time (the end of 2005). Turbine hub heights in the sample range from a minimum of 50 meters in the Washington/Oregon (WAOR) study area, to a maximum of 80 meters (TXHC, OKCC and PASC), with nine of the ten study areas having hub heights of at least 65 meters. The sites include a diverse variety of land types, including combinations of ridgeline (WAOR, PASC, and PAWC), rolling hills (ILLC, WIKCDC, NYMCOC, and NYMC), mesa (TXHC), and windswept plains (OKCC, IABV). ${ }^{6}$

\footnotetext{
${ }^{6}$ Some areas, such as PASC, have both a ridgeline and rolling hills on which wind facilities are located.
} 


\subsection{Data Collection}

For each study area, residential transaction data in as close proximity to the wind turbines as possible was sought, from both before and after wind facility construction. To balance the cost and quantity of data collection in each study area with the desire to cover as many study areas as possible, the research effort sought to collect data on 400 to 1,250 transactions in each study area. $^{7}$ In some instances, this meant including all residential transactions within ten miles of the wind turbines. In others, only transactions within five miles were included. In some extreme instances, when the number of transactions inside of five miles exceeded the 1,250 limit, all transactions in close proximity to the wind turbines (e.g., inside three miles) were included in combination with a random sample of transactions outside of that distance band (e.g., between three and five miles).

Three primary sets of data are used in the analysis: tabular data, geographic information system (GIS) data, and field data, each of which is discussed below. Special attention is given to the field data collection process for the two qualitative variables that are essential to the analysis that follows: scenic vista and views of turbines.

\subsection{Tabular Data}

Tabular sales transaction data were obtained from participating countries totaling 7,459 "valid" transactions of single family residential homes, on less than 25 acres, which were sold for a price of more than $\$ 10,000$, which occurred after January 1, 1996, and which had fully populated

\footnotetext{
${ }^{7}$ This range was chosen to ensure that a minimum amount of data were present in each study area to allow for a robust analysis, and yet not too much so as to make data collection (e.g., the visiting of each home) inordinately time and resource consuming in any individual study area.
} 
“core” home characteristics. ${ }^{8}$ These core characteristics were: number of square feet of the living area (excluding finished basement), acres of land, number of bathrooms and fireplaces, year built, type of exterior walls (stone or not), presence of central air conditioning and a finished basement, and the exterior condition of the home. The 7,459 residential transactions in the sample consist of 6,194 unique homes (a number of the homes in the sample sold more than once in the selected study period). In addition to the home characteristic data, each county provided, at a minimum, the home’s physical address and sales price. Finally, market-specific quarterly housing inflation indexes were obtained from Freddie Mac, which allowed nominal sales prices to be adjusted to 1996 dollars. ${ }^{9}$

\subsection{GIS Data}

GIS data on parcel location and shape were also required, and were obtained from the individual counties. The counties also often provided GIS layers for roads, water courses, water bodies, wind turbines (in some cases), and house locations. Other GIS data were obtained, as was necessary, from the U.S. Department of Agriculture (USDA). ${ }^{10}$ Combined, these data allowed each home to be identified in the field; the construction of a GIS layer of wind turbine locations

\footnotetext{
${ }^{8}$ In some cases, county officials extracted data from their database directly, while in other cases a company engaged to manage a county’s data provided the necessary information. In either case, the provider is referred to as “county." Detailed descriptions of the providers, the data collection process, and how the data are arrayed across the variables of interest are available upon request.

${ }^{9}$ Freddie Mac Conventional Mortgage Home Price Index: municipal statistical area (MSA) series data are available from the following site: http://www.freddiemac.com/finance/cmhpi/. Because most of the study areas do not fall within the MSAs, a collection of local experts was relied upon, including real estate agents, assessors, and appraisers, to decide which MSA most-closely matched that of the local market. In all cases, the experts had consensus as to the best MSA to use. In one case (NYMCOC), the sample was split between two MSAs.

10 These data were sourced from the USDA Geospatial Data Gateway: http://datagateway.nrcs.usda.gov/GatewayHome.html.
} 
for each facility; and the calculation of the distance from each home to the nearest wind turbine. As a result, each transaction was assigned a unique distance ("DISTANCE") 11 that was determined as the distance between the home and nearest wind turbine at the time of sale. For the purpose of three of the four hedonic models, these distances are grouped into five categories: (1) inside of 3000 feet (0.57 miles); (2) between 3000 feet and one mile; (3) between one and three miles; (4) between three and five miles; and (5) outside of five miles. ${ }^{12}$ Finally, the GIS data were used to discern if the home was situated on a cul-de-sac and had water frontage, both of which were corroborated in the field.

\subsection{Field Data}

Additional data had to be collected through field visits to all homes in the sample. Two qualitative measures in particular - scenic vista and view of the wind turbines - are discussed in detail because each is essential to the analysis and each required some amount of professional judgment in its creation.

The impact or severity of the view of wind turbines ("VIEW") ${ }^{13}$ may be related to some combination of the number of turbines that are visible, the amount of each turbine that is visible (e.g., just the tips of the blades or all of the blades and the tower), the distance to the nearest turbines, the direction that the turbines are arrayed in relation to the viewer (e.g., parallel or

\footnotetext{
${ }^{11}$ Distance measures are collectively and individually referred to as "DISTANCE” from this point forward. The variable DISTANCE was constructed using the Euclidean distance between each property and the nearest turbine at the time of sale. A full description of the method for deriving distance to the nearest turbine for each home is available from the authors upon request.

12 The minimum distance of “inside 3000 feet” was chosen because it was the closest cutoff that still provided an ample supply of data for analysis.

${ }^{13}$ View of turbines rankings are collectively and individually referred to as "VIEW" from this point forward.
} 
perpendicular), the contrast of the turbines to their background, and the degree to which the turbine arrays are harmoniously placed into the landscape (Gipe, 2002). Recent efforts have made some progress in developing quantitative measures of the aesthetic impacts of wind turbines (Torres-Sibillea et al., 2009), but, at the time this project began, few measures had been developed, and those that had been developed were difficult to apply in the field (e.g., Bishop, 2002). As a result, an ordered qualitative VIEW ranking system that consists of placing the view of turbines into one of five possible categories is opted for: (1) NO VIEW; (2) MINOR; (3) MODERATE; (4) SUBSTANTIAL; and (5) EXTREME. These rankings were developed to encompass considerations of distance, number of turbines visible, and viewing angle into one ordered categorical scale (see Table 2 ). ${ }^{14}$

\footnotetext{
${ }^{14}$ In addition to the qualitative rating system that was ultimately used in this study, a variety of quantitative data were collected that might describe the nature of the view of wind turbines, including the total number of turbines visible, the distance of the home to the nearest wind turbine, and the view scope/viewing angle (i.e., the degree to which the turbines spread out in front of the home: narrow, medium, or wide). To explore the validity of the qualitative rating scale two tests were conducted. First, a pre-study survey was conducted by showing 10 different off-site respondents 15 randomly selected photographs from the field representing the various rated VIEW categories. The higher VIEW rankings were oversampled to create a roughly equal distribution among the categories. The respondents rated the views into one of the qualitative categories. The on-site / field collected rankings matched the off-site responses $65 \%$ of the time, with $97 \%$ of the rankings differing by no more than one category. Ninety-eight percent of the on-site-ranked MINOR VIEWs and 89\% of the EXTREME VIEWs were similarly ranked by off-site respondents. The on-site rankings were less than the off-site rankings $97 \%$ of the time; it is assumed that this is because on-site rankings took into account a greater portion of the panorama than was captured in the photos, which translated into a lower ranking. Secondly, a post hoc Multinomial Logistic Regression model was created that used the qualitative on-site VIEW rankings as the dependent variable and the quantitative measures of distance to nearest turbine, number of turbines visible, and view scope as the independent variables. This model produced high Pseudo $\mathrm{R}^{2}$ statistics (Cox and Snell 0.88, Nagelkerke 0.95, and McFadden 0.79) and predicted values that were highly correlated with the actual qualitative rating (Pearson's 0.88). Therefore, both tests corroborated the appropriateness of the simpler qualitative VIEW rankings used herein.
} 
Table 2: Definition of VIEW Categories

\begin{tabular}{|l|l|}
\hline NO VIEW & The turbines are not visible at all from this home. \\
\hline MINOR VIEW & $\begin{array}{l}\text { The turbines are visible, but the scope (viewing angle) is narrow, there are } \\
\text { many obstructions, or the distance between the home and the facility is } \\
\text { large. }\end{array}$ \\
\hline MODERATE VIEW & $\begin{array}{l}\text { The turbines are visible, but the scope is either narrow or medium, there } \\
\text { might be some obstructions, and the distance between the home and the } \\
\text { facility is most likely a few miles. }\end{array}$ \\
\hline SUBSTANTIAL VIEW & $\begin{array}{l}\text { The turbines are dramatically visible from the home. The turbines are } \\
\text { likely visible in a wide scope and most likely the distance between the } \\
\text { home and the facility is short. }\end{array}$ \\
\hline EXTREME VIEW & $\begin{array}{l}\text { This rating is reserved for sites that are unmistakably dominated by the } \\
\text { presence of the wind facility. The turbines are dramatically visible from } \\
\text { the home and there is a looming quality to their placement. The turbines } \\
\text { are often visible in a wide scope or the distance to the facility is very } \\
\text { small. }\end{array}$ \\
\hline
\end{tabular}

In addition to the qualitative VIEW measurements, a rating for the quality of the scenic vista ("VISTA") ${ }^{15}$ from each home, absent the existence of the wind facilities, was also collected in the field. An assessment of the quality of the VISTA from each home was needed because VIEW and VISTA are expected to be correlated; for example, homes with a PREMIUM VISTA are more likely to have a wide viewing angle in which wind turbines might also be seen.

Therefore, to accurately measure the impacts of the VIEW of wind turbines on property values a concurrent control for VISTA (independent of any views of turbines) was required. Drawing heavily on the landscape-quality rating system developed by Buhyoff et al. (1994) and to a lesser degree on the systems described by others (Daniel and Boster, 1976; USDA, 1995), an ordered

\footnotetext{
${ }^{15}$ Scenic vista rankings are individually and collectively referred to as "VISTA" from this point forward.
} 
VISTA ranking system consisting of five categories was developed: (1) POOR; (2) BELOW

AVERAGE; (3) AVERAGE; (4) ABOVE AVERAGE; and (5) PREMIUM (see Table 3). ${ }^{16}$

\section{Table 3: Definition of VISTA Categories}

\begin{tabular}{|l|l|}
\hline POOR VISTA & $\begin{array}{l}\text { These vistas are often dominated by visually discordant man-made } \\
\text { alterations (not considering turbines), or are uncomfortable spaces for } \\
\text { people, lack interest, or have virtually no recreational potential. }\end{array}$ \\
\hline BELOW AVERAGE VISTA & $\begin{array}{l}\text { These scenic vistas contain visually discordant man-made alterations (not } \\
\text { considering turbines) but are not dominated by them. They are not inviting } \\
\text { spaces for people, but are not uncomfortable. They have little interest or } \\
\text { mystery and have minor recreational potential. }\end{array}$ \\
\hline AVERAGE VISTA & $\begin{array}{l}\text { These scenic vistas include interesting views that can be enjoyed often only } \\
\text { in a narrow scope. These vistas may contain some visually discordant man- } \\
\text { made alterations (not considering turbines), are moderately comfortable } \\
\text { spaces for people, have some interest, and have minor recreational potential. }\end{array}$ \\
\hline PREMIUM VISTA & $\begin{array}{l}\text { These scenic vistas include interesting views that often can be enjoyed in a } \\
\text { medium to wide scope. They might contain some man-made alterations (not } \\
\text { considering turbines), yet still possess significant interest and mystery, are } \\
\text { moderately balanced and have some potential for recreation. }\end{array}$ \\
\hline & $\begin{array}{l}\text { These scenic vistas would include "picture postcard" views that can be } \\
\text { enjoyed in a wide scope. They are often free or largely free of any discordant } \\
\text { man made alterations (not considering turbines), possess significant interest, } \\
\text { memorable qualities, and mystery and are well balanced and likely have a } \\
\text { high potential for recreation. }\end{array}$ \\
\hline
\end{tabular}

${ }^{16}$ The appropriateness of these rankings was tested in two ways. First, a set of 34 pictures taken on-site and representing various categories of VISTA were shown to 10 off-site respondents who were asked to rank them using the same categories, and then explain why they rated them as such. Although the off-site rankings matched the onsite rankings only $51 \%$ of the time, $94 \%$ of on- and off-site rankings differed by no more than one category, with $17 \%$ of the off-site rankings being one ranking below the on-site and $26 \%$ one ranking above. The descriptions of why the rankings were chosen by the off-site respondents illuminated the fact that off-site rankings did not take into account a number of aspects that were not adequately captured in the photos, but that were apparent in the field. This finding was borne out by a second test that had five individuals visit seven homes in the field to rank their scenic vistas. When all respondents were on-site, they similarly ranked the vista $72 \%$ of the time, with a ranking that differed by no more than one category occurring one hundred percent of the time. Therefore, both tests corroborated the appropriateness of the simpler qualitative VISTA rankings used herein. 
Field data collection was conducted on a house-by-house basis. Each of the 6,194 homes was visited by the same individual to remove a potential source of bias among field rankings. Data collection was conducted in the fall of 2006, and the spring, summer, and fall of 2007 and 2008. Each house was photographed and, when appropriate, so too were views of turbines and the prominent scenic vista. ${ }^{17}$ Data on VIEW were collected only for those homes that sold after at least one wind power facility had been erected in the study area. When multiple wind facilities, with different construction dates, were visible from a home, field rankings for VIEW were made by taking into account which turbines had been erected at the time of sale. Additionally, if the season at the time of sale differed from that of data collection (e.g., if leaves were off the trees for one but on for the other), an effort was made to modulate the VIEW rating accordingly. ${ }^{18}$

Both VIEW and VISTA field rankings were arrived at through a Q-Sort method (Pitt and Zube, 1979), which is used to distinguish relatively similar rankings. For views of turbines, the rater first determined if the ranking was MINOR or EXTREME. If neither of these two rankings was appropriate, then only a choice between MODERATE and SUBSTANTIAL was required. Similarly, for VISTA rankings, first POOR and PREMIUM were distinguished from the others; if neither applied then BELOW AVERAGE or ABOVE AVERAGE could be selected. If neither of those were appropriate, the VISTA, by default, was considered AVERAGE. In all cases, if wind turbines were visible from the home, the VISTA rankings were made as if those turbines did not exist.

\footnotetext{
${ }^{17}$ Photographic examples of each VIEW and VISTA rating are available upon request from the authors.

${ }^{18}$ This "modulation" occurred only for trees in the foreground, where, for instance, a single tree could obscure the view of turbines; this was not the case for trees nearer the horizon.
} 


\subsection{Data Summary}

The final dataset consists of 7,459 valid residential transactions occurring between January 2, 1996 and June 30, 2007. Those transactions are arrayed across time and the ten wind project study areas as shown in Table 4. The sample of transactions ranges from 412 in Lee County, Illinois (ILLC) to 1,311 in Howard County, Texas (TXHC). A basic summary of the resulting dataset, including the many independent variables used in the hedonic models described later, is contained in Table 5 and Table 6. These tables present summary information for the full dataset (7,459 transactions) as well as the post-construction subset of that dataset (4,937 transactions); the latter is provided because some of the models (specifically Models One and Two described below) focus on homes that sold after wind facility construction. ${ }^{19}$ Finally,Table 7 describes how the distance variable is arrayed across time, data that are used in Models Three and Four.

\footnotetext{
${ }^{19}$ The construction, online dates, and announcement dates were provided by Energy Velocity, LLC. The announcement date corresponds to the first time the facility appears in the public record, which was often the permit application date. This constitutes the first well established date when the wind facility would have been likely known by the public, and therefore is appropriate to use for this analysis. Nonetheless, there remain a number of areas for potential bias in this date. First, the permit application date might be preceded by news reports of the impending application; alternatively, if the public record was not published online, the "announcement" date - as used here - could, in fact, follow the permit application date. To address this possible concern, when possible, the authors had discussions with the developer of the wind facility. In most cases, the Energy Velocity dates were found to be accurate, and when they were not they were adjusted to reflect the dates provided by the developer. A second potential source of bias is the possibility that a different project was proposed but never built, but that influenced the residential market in the study area prior to the "announcement” date. Although this is likely rare, the authors are aware of at least a few projects that fit that description in the study areas. A final source of bias might revolve around the likelihood that awareness of a project could occur even before the facility was formally announced. For example, a community member might know that a wind facility is being considered because they had been approached by the wind development company well ahead of a public announcement. In turn, they might have had private discussions regarding the facility with other members of the community. Taken together, it is appropriate to assume that there is some bias in the "announcement" date, and that awareness of the project might precede the date used in this analysis. The impact of this bias is addressed further below.
} 
The mean nominal residential transaction price in the full sample is $\$ 102,968$, or $\$ 79,114$ in 1996 dollars. The average (mean) house in the sample was 46 years old, situated on 1.13 acres, with 1,620 square feet of finished living area above ground, 1.74 bathrooms, and a slightly better than average condition. 730 homes in the sample sold with a view of the turbines, with 169 being a higher ranking than MINOR (e.g., MODERATE, etc.) 125 homes in the sample are located within a mile and sold after the facility was constructed, and 145 homes are located within a mile and sold after the facility was announced (which also includes the period after construction).

Table 4: Summary of Transactions across Study Areas and Development Periods

\begin{tabular}{|c|c|c|c|c|c|c|}
\hline & $\begin{array}{c}\text { Pre } \\
\text { Announcement }\end{array}$ & $\begin{array}{c}\text { Post } \\
\text { Announcement } \\
\text { Pre } \\
\text { Construction } \\
\end{array}$ & \begin{tabular}{|c|} 
1st Year \\
After \\
Construction
\end{tabular} & $\begin{array}{c}\text { 2nd Year } \\
\text { After } \\
\text { Construction }\end{array}$ & $\begin{array}{c}2+\text { Years } \\
\text { After } \\
\text { Construction }\end{array}$ & Total \\
\hline $\begin{array}{l}\text { Benton/Walla Walla, WA \& Umatilla, } \\
\text { OR (WAOR) }\end{array}$ & 226 & 45 & 76 & 59 & 384 & 790 \\
\hline Howard, TX (TXHC) & 169 & 71 & 113 & 131 & 827 & 1311 \\
\hline Custer, OK (OKCC) & 484 & 153 & 193 & 187 & 96 & 1113 \\
\hline Buena Vista, IA (IABV) & 152 & 65 & 80 & 70 & 455 & 822 \\
\hline Lee, IL (ILLC) & 115 & 84 & 62 & 71 & 80 & 412 \\
\hline Kewaunee/Door, WI (WIKCDC) & 44 & 41 & 68 & 62 & 595 & 810 \\
\hline Somerset, PA (PASC) & 175 & 28 & 46 & 60 & 185 & 494 \\
\hline Wayne, PA (PAWC) & 223 & 106 & 64 & 71 & 87 & 551 \\
\hline Madison/Oneida, NY (MYMCOC) & 108 & 9 & 48 & 30 & 268 & 463 \\
\hline Madison, NY (NYMC) & 59 & 165 & 74 & 70 & 325 & 693 \\
\hline TOTAL & 1755 & 767 & 824 & 811 & 3302 & 7459 \\
\hline
\end{tabular}


Table 5: Summary Statistics: All Sales and Post-Construction Sales

\begin{tabular}{|c|c|c|c|c|c|c|c|}
\hline \multirow[b]{2}{*}{ Variable Name } & \multirow[b]{2}{*}{ Description } & \multicolumn{3}{|c|}{ All Sales } & \multicolumn{3}{|c|}{ Post Construction Sales } \\
\hline & & Freq. * & Mean & Std. Dev. & Freq. * & Mean & Std. Dev. \\
\hline SalePrice & The unadjusted sale price of the home (in US dollars) & 7,459 & 102,968 & 64,293 & 4,937 & 110,166 & 69,422 \\
\hline SalePrice96 & The sale price of the home adjusted to 1996 US dollars & 7,459 & 79,114 & 47,257 & 4,937 & 80,156 & 48,906 \\
\hline LN_SalePrice96 & $\begin{array}{l}\text { The natural log transformation of the sale price of the home } \\
\text { adjusted to } 1996 \text { US dollars }\end{array}$ & 7,459 & 11.12 & 0.58 & 4,937 & 11.12 & 0.60 \\
\hline AgeatSale & The age of the home at the time of sale & 7,459 & 46 & 37 & 4,937 & 47 & 36 \\
\hline AgeatSale_Sqrd & The age of the home at the time of sale squared & 7,459 & 3,491 & 5,410 & 4,937 & 3,506 & 5,412 \\
\hline Sqft_1000 & $\begin{array}{l}\text { The number of square feet of above grade finished living area } \\
\text { (in 1000s) }\end{array}$ & 7,459 & 1.623 & 0.59 & 4,937 & 1.628 & 0.589 \\
\hline Acres & The number of Acres sold with the residence & 7,459 & 1.13 & 2.42 & 4,937 & 1.10 & 2.40 \\
\hline Baths & The number of Bathrooms (Full Bath $=1$, Half Bath $=0.5$ ) & 7,459 & 1.74 & 0.69 & 4,937 & 1.75 & 0.70 \\
\hline ExtWalls_Stone & $\begin{array}{l}\text { If the home has exterior walls of stone, brick or stucco } \\
\qquad(\text { Yes }=1, \text { No }=0)\end{array}$ & 2,287 & & & 1,486 & & \\
\hline CentralAC & If the home has a Central AC unit $($ Yes $=1, \mathrm{No}=0$ ) & 3,785 & & & 2,575 & & \\
\hline Fireplace & The number of fireplace openings & 2,708 & 0.39 & 0.55 & 1,834 & 0.40 & 0.55 \\
\hline Cul_De_Sac & If the home is situated on a cul-de-sac $($ Yes $=1, \mathrm{No}=0)$ & 990 & & & 673 & & \\
\hline FinBsmt & $\begin{array}{l}\text { If finished basement square feet is greater than } 50 \% \text { times first } \\
\text { floor square feet (Yes }=1, \text { No }=0 \text { ) }\end{array}$ & 1,472 & & & 992 & & \\
\hline Water_Front & $\begin{array}{l}\text { If the home shares a property line with a body of water or river } \\
\qquad(\text { Yes }=1, \text { No }=0)\end{array}$ & 107 & & & 87 & & \\
\hline Cnd_Low & If the condition of the home is Poor $(\mathrm{Yes}=1, \mathrm{No}=0)$ & 101 & & & 69 & & \\
\hline Cnd_BAvg & If the condition of the home is Below Average $($ Yes $=1$, No $=0)$ & 519 & & & 359 & & \\
\hline Cnd_Avg & If the condition of the home is Average (Yes = 1, No $=0$ ) & 4,357 & & & 2,727 & & \\
\hline Cnd_AAvg & $\begin{array}{l}\text { If the condition of the home is Above Average } \\
\qquad(\text { Yes }=1, \text { No }=0)\end{array}$ & 2,042 & & & 1,445 & & \\
\hline Cnd_High & If the condition of the home is High $($ Yes $=1$, No $=0$ ) & 440 & & & 337 & & \\
\hline Vista_Poor & If the Scenic Vista from the home is Poor $($ Yes $=1$, No $=0$ ) & 470 & & & 310 & & \\
\hline Vista_BAvg & $\begin{array}{l}\text { If the Scenic Vista from the home is Below Average } \\
\qquad(\text { Yes }=1, \text { No }=0)\end{array}$ & 4,301 & & & 2,857 & & \\
\hline Vista_Avg & If the Scenic Vista from the home is Average (Yes $=1$, No $=0$ ) & 1,912 & & & 1,247 & & \\
\hline Vista_AAvg & $\begin{array}{l}\text { If the Scenic Vista from the home is Above Average } \\
\qquad(\text { Yes }=1 \text {, No=0) }\end{array}$ & 659 & & & 448 & & \\
\hline Vista_Prem & If the Scenic Vista from the home is Premium $($ Yes $=1$, No $=0)$ & 117 & & & 75 & & \\
\hline SaleYear & The year the home was sold & 7,459 & 2002 & 2.9 & 4,937 & 2004 & 2.3 \\
\hline
\end{tabular}

* "Freq." applies to the number of cases the parameter's value is not zero 
Table 6: Summary of Variables of Interest: All Sales and Post-Construction Sales

\begin{tabular}{|c|c|c|c|c|c|c|c|}
\hline \multirow[b]{2}{*}{ Variable Name } & \multirow[b]{2}{*}{ Description } & \multicolumn{3}{|c|}{ All Sales } & \multicolumn{3}{|c|}{ Post Construction Sales } \\
\hline & & Freq. * & Mean & Std. Dev. & Freq. * & Mean & Std. Dev. \\
\hline View_None & $\begin{array}{l}\text { If the home sold after construction began and had no view of the } \\
\text { turbines (Yes }=1, \text { No }=0)\end{array}$ & 4,207 & & & 4,207 & & \\
\hline View_Minor & $\begin{array}{l}\text { If the home sold after construction began and had a Minor View } \\
\left.\text { of the turbines (Yes }=1, \mathrm{No}_{0}=0\right)\end{array}$ & 561 & & & 561 & & \\
\hline View_Mod & $\begin{array}{l}\text { If the home sold after construction began and had a Moderate } \\
\text { View of the turbines (Yes }=1, \mathrm{No}=0 \text { ) }\end{array}$ & 106 & & & 106 & & \\
\hline View_Sub & $\begin{array}{l}\text { If the home sold after construction began and had a Substantial } \\
\left.\text { View of the turbines (Yes }=1, \mathrm{No}_{0}=0\right)\end{array}$ & 35 & & & 35 & & \\
\hline View_Extrm & $\begin{array}{l}\text { If the home sold after construction began and had a Extreme } \\
\text { View of the turbines (Yes }=1, \mathrm{No}=0 \text { ) }\end{array}$ & 28 & & & 28 & & \\
\hline DISTANCE $\dagger$ & $\begin{array}{l}\text { Distance to nearest turbine if the home sold after facility } \\
\text { "announcement", otherwise } 0\end{array}$ & 5,705 & 2.53 & 2.59 & 4,895 & 3.57 & 1.68 \\
\hline Mile_Less_0.57† & $\begin{array}{l}\text { If the home sold after facility "announcement" and was within } \\
0.57 \text { miles (3000 feet) of the turbines } \\
\text { (Yes }=1, \mathrm{No}=0 \text { ) }\end{array}$ & 80 & & & 67 & & \\
\hline Mile_0.57to1 † & $\begin{array}{l}\text { If the home sold after facility "announcement" and was between } \\
0.57 \text { miles ( } 3000 \text { feet) and } 1 \text { mile of the turbines } \\
\text { (Yes }=1, \mathrm{No}=0)\end{array}$ & 65 & & & 58 & & \\
\hline Mile_1to3 † & $\begin{array}{l}\text { If the home sold after facility "announcement" and was between } \\
1 \text { and } 3 \text { miles of the turbines (Yes }=1, \mathrm{No}=0 \text { ) }\end{array}$ & 2,359 & & & 2,019 & & \\
\hline Mile_3to5 † & $\begin{array}{l}\text { If the home sold after facility "announcement" and was between } \\
3 \text { and } 5 \text { miles of the turbines (Yes }=1, \mathrm{No}=0 \text { ) }\end{array}$ & 2,200 & & & 1,923 & & \\
\hline Mile_Gtr5 † & $\begin{array}{l}\text { If the home sold after facility "announcement" and was outside } 5 \\
\text { miles of the turbines (Yes }=1, \text { No }=0 \text { ) }\end{array}$ & 1,000 & & & 870 & & \\
\hline
\end{tabular}

\footnotetext{
* "Freq." applies to the number of cases the parameter's value is not zero

† "All Sales" freq., mean and standard deviation DISTANCE and DISTANCE fixed effects variables (e.g., Mile_1to3) include transactions that occurred after
} facility "announcement" and before "construction" as well as those that occured post-construction

\section{Table 7: Frequency Crosstab of DISTANCE and PERIOD}

\begin{tabular}{|c|c|c|c|c|c|c|c|}
\hline & $\begin{array}{c}\text { More Than } 2 \text { Years } \\
\text { Before } \\
\text { Announcement }\end{array}$ & $\begin{array}{c}\text { Less Than } 2 \text { Years } \\
\text { Before } \\
\text { Announcement }\end{array}$ & $\begin{array}{c}\text { After } \\
\text { Announcement } \\
\text { Before } \\
\text { Construction } \\
\end{array}$ & $\begin{array}{c}\text { Less Than } 2 \\
\text { Years After } \\
\text { Construction }\end{array}$ & $\begin{array}{c}\text { Between } 2 \text { and } 4 \\
\text { Years After } \\
\text { Construction }\end{array}$ & $\begin{array}{c}\text { More Than } 4 \\
\text { Years After } \\
\text { Construction }\end{array}$ & Total \\
\hline Inside 3000 Feet & 23 & 22 & 13 & 22 & 23 & 22 & 125 \\
\hline Between 3000 Feet and 1 Mile & 15 & 18 & 7 & 17 & 22 & 21 & 100 \\
\hline Between 1 and 3 Miles & 283 & 592 & 340 & 806 & 502 & 709 & 3,232 \\
\hline Between 3 and 5 Miles & 157 & 380 & 277 & 572 & 594 & 757 & 2,737 \\
\hline Outside of 5 Miles & 132 & 133 & 130 & 218 & 227 & 425 & 1,265 \\
\hline TOTAL & 610 & 1,145 & 767 & 1,635 & 1,368 & 1,934 & 7,459 \\
\hline
\end{tabular}




\section{Model Estimation}

In the sections that follow, a series of hedonic models is estimated to assess whether residential sales prices are affected by views of and proximity to wind power facilities in a statistically measurable way. In so doing, the presence of the three potential property value stigmas associated with wind energy facilities is simultaneously tested for: area, scenic vista, and nuisance. All of the models that are estimated have four sets of parameters. One of these is associated with the variables of interest (DISTANCE and VIEW), and the other three sets are associated with controls that include home and site characteristics, study-area fixed effects, and spatial adjustments. ${ }^{20}$ The models differ in their specification and testing of the variables of interest, but use the same set of controls. ${ }^{21}$

${ }^{20}$ It should be emphasized that in Model One, and in all subsequent models, all variables of interest, spatial adjustments, and home and site characteristics are pooled, and therefore their estimates represent the average across all study areas. Ideally, one would have enough data to estimate a model at the study area level - a fully unrestricted model - rather than pooled across all areas. This fully unrestricted model form, along with 15 other model forms (with some variables restricted and others not) were therefore investigated (results from which will be provided upon request). In particular, these 16 different models were estimated to explore which model was the most parsimonious (had the fewest parameters), performed the best (e.g., had the highest adjusted $\mathrm{R}^{2}$ and the lowest Schwarz information criterion), and had the most stable coefficients and standard errors. The pooled model, as described by equations 1-4 was found to fit that description. By making this choice, the present research concentrates on identifying the presence of potential property value impacts across all of the study areas in the sample as opposed to any single study area. Because effects might vary between study areas, and the models estimate an average across all study areas, the full range of effects in individual study areas will go undetermined. That notwithstanding, there is no reason to suspect that effects will be completely "washed out." For that to occur, an effect in one study area would have to be positive while in another area it would have to be negative, and there is no reason to suspect that residential sales prices would increase because of the turbines in one community while decreasing in other communities.

${ }^{21}$ It should be emphasized that the results presented here are robust regardless of whether the controlling variables are pooled across all study areas or estimated at the study area level. 


\subsection{Controls}

The three sets of controls are as follows:

\subsubsection{Home and Site Characteristics}

This set of variables controls for home and site-specific characteristics such as age of the home (linear and squared), square feet, acres, number of bathrooms and fireplaces, the condition of the home, the quality of the scenic vista from the home, the presence of central air conditioning, a stone exterior, and/or a finished basement, and whether the home is located in a cul-de-sac and/or on a waterfront. ${ }^{22}$ In the case of condition (of the home) and scenic vista variables, the reference cases are average condition and average scenic vista respectively.

\subsubsection{Study Area Fixed Effects}

The study area fixed effects variables control for study area influence. The estimated coefficients for this group of variables capture the combined effects of school districts, tax rates, crime, and other location influences across an entire study area. Although this approach greatly simplifies the estimation of the model, interpreting the coefficients can be difficult because of the myriad of influences captured by these study-area fixed effects variables. The reference category is the Washington/Oregon (WAOR) study area. ${ }^{23}$

\footnotetext{
${ }^{22}$ Although the number of bedrooms can be an indicator of value, it is highly correlated with square feet and bathrooms, and therefore was not included in the analysis because it did not add explanatory value.

${ }^{23}$ Because there is no intent to focus on the coefficients of the study area fixed effect variables, the reference case is arbitrary. Further, the results for the other variables in the model are completely independent of this choice. Finally, although models using study area fixed effects are presented here, the hedonic results are robust to the alternative of including school district and census tract variables in addition to the study area fixed effects variables.
} 


\subsubsection{Spatial Adjustments}

Since the sales price of a home is usually influenced by the sales prices of homes in the same neighborhood, ignoring the underlying spatial dependence in the data could bias the OLS estimates (Espey et al., 2007). The spatial dependence among the prices of homes can take two forms: spatial autocorrelation and spatial heterogeneity. The former captures the direct effect of neighboring properties on the value of a given property, and the latter accounts for the correlation among unobservables that affect property values in a given neighborhood. The inclusion of study area fixed effects likely reduces spatial heterogeneity to an extent that it is no longer a serious concern. ${ }^{24}$ However, this should/could be verified in a future study. ${ }^{25}$ Spatial autocorrelation, meanwhile, is addressed by including a spatially weighted sales price $(\mathrm{N})$ for each home that was calculated using the estimated sales prices of the five nearest neighbors within the six preceding months. ${ }^{26}$

\subsection{Model One}

As noted above, the dataset consists of 7,459 residential transactions, of which 2,522 transactions occurred before the wind facility was constructed. Analysis begins with the simplest of the models in which only the 4,937 post-construction transactions is used. As is common in the

\footnotetext{
${ }^{24}$ Multiple models were estimated with various micro-spatial effects included such as school district, census tract, township, and, where possible, neighborhood. The results are robust to their inclusion or exclusion.

${ }^{25}$ Verifying the existence, or lack thereof, of spatial heterogeneity (via Moran's I) was not possible given the computing power available for this research and the large dataset.

${ }^{26}$ This definition of "nearest neighbors" was chosen to mimic the selection process of a set of comparables for appraisers and/or realtors. The hedonic model was also run with this variable excluded, with no meaningful differences in results.
} 
literature (Malpezzi, 2003; Sirmans et al., 2005b; Simons and Saginor, 2006), a semi-log functional form is used where the dependent variable, the (natural log of) sales price (P), is measured in inflation-adjusted (1996) dollars.

The literature on environmental disamenities often uses a continuous variable for the distance from the home to the disamenity in question (e.g., Sims et al., 2008). A number of different functional forms can be used for a continuous DISTANCE variable, including linear, inverse, cubic, quadratic, logarithmic and spline. Of the forms that were considered, the linear spline seemed most appropriate for this purpose. Spline functions are used when it is assumed that a marginal change in sale price per unit of distance is not constant across all distances from a disamenity and that those effects should be estimated separately. This form dovetails well with area and nuisance stigma definitions, wherein an effect based on distance can be estimated across the entire sample of homes (area stigma) and separately for those homes inside of one mile (nuisance stigma). ${ }^{27}$ Therefore, the following model is estimated:

$$
\begin{aligned}
\ln (\mathrm{P})= & \beta_{0}+\beta_{1} \mathrm{~N}+\sum_{\mathrm{s}} \beta_{2} \mathrm{~S}+\sum_{\mathrm{k}} \beta_{3} \mathrm{X}+\sum_{\mathrm{v}} \beta_{4} \mathrm{VIEW}+ \\
& \beta_{5} \text { DISTANCE }+\beta_{6}((\text { DISTANCE }-1) \cdot \text { LT1MILE })+\varepsilon
\end{aligned}
$$

where $\mathrm{N}$ is the spatially weighted neighbors' predicted sales price, $\mathrm{S}$ is the vector of $s$ study area fixed effects variables (e.g., TXHC, OKCC), $\mathrm{X}$ is a vector of $k$ home and site characteristics, (e.g., acres, square feet), VIEW is a vector of $v$ categorical turbine view variables (e.g., MINOR,

\footnotetext{
${ }^{27}$ Other distance functions (e.g., linear, quadratic, cubic, logarithmic and inverse) were also tested. Results from these models are briefly discussed below.
} 
MODERATE), DISTANCE is the measurement (in miles) from the home to the nearest turbine at the time of sale, and LT1MILE equals 1 when the DISTANCE is less than one mile, and 0 otherwise, $\beta_{0}$ is the constant or intercept across the full sample, $\beta_{1}$ is a parameter estimate for the spatially weighted neighbor's predicted sales price, $\beta_{2}$ is a vector of $s$ parameter estimates for the study area fixed effects as compared to homes sold in the Washington/Oregon (WAOR) study area, $\beta_{3}$ is a vector of $k$ parameter estimates for the home and site characteristics, $\beta_{4}$ is a vector of $v$ parameter estimates for the VIEW variables as compared to homes sold with no view of the turbines, $\beta_{5}$ is a parameter estimate for the effect DISTANCE has on sale price across all homes, $\beta_{6}$ is a parameter estimate for the additive effect DISTANCE has on sale price for those homes inside of one mile, and $\varepsilon$ is a random disturbance term. ${ }^{28}$

If a significant scenic vista stigma exists in this model and all subsequent models, one would expect the coefficients of VIEW to be negative, significant and monotonically decreasing from EXTREME to MINOR. The effect of area stigma is expected to be captured through the variable DISTANCE and the effect of nuisance stigma through the variable (DISTANCE1)*LT1MILE. If these stigmas exist, the coefficients of these variables are expected to be positive and significant, indicating an increase in selling prices for each mile the homes are further from the wind turbines.

\footnotetext{
${ }^{28}$ Both VIEW and DISTANCE appear in the model together because a home's value may be affected in part by the magnitude of the view of the wind turbines, and, in part by the distance from the home to those turbines.
} 


\subsection{Model Two}

Though the continuous form of DISTANCE, as used in Model One, is consistent with the previous literature, it imposes a rigid structure on the dataset that may lead to specification errors. Model Two relaxes this rigidity by measuring DISTANCE in categorical form. In this model, the reference category for DISTANCE is the set of home transactions for homes that are situated outside of five miles from the nearest wind turbine. The reference homes were chosen on the basis of the argument that these homes are least likely to be affected by the presence of the wind facilities. ${ }^{29}$ Other than this change, the dataset used for the estimation, the list of controls, and the specification of the VIEW variable remain unchanged relative to Model One. Therefore, the following model is estimated:

$\ln (\mathrm{P})=\beta_{0}+\beta_{1} \mathrm{~N}+\sum_{\mathrm{s}} \beta_{2} \mathrm{~S}+\sum_{\mathrm{k}} \beta_{3} \mathrm{X}+\sum_{\mathrm{v}} \beta_{4} \mathrm{VIEW}+\sum_{\mathrm{d}} \beta_{5} \mathrm{DISTANCE}+\varepsilon$

where DISTANCE is a vector of $d$ categorical distance to turbine variables (e.g., less than 3000 feet, between 3000 feet and one mile), the reference category being homes situated outside of five miles. All other variables are as described in Model One.

Since the VIEW variable is unchanged, it is expected to capture the effect of scenic vista stigma in a manner identical to Model One. It is assumed that nuisance effects are largely concentrated within one mile of the nearest wind turbine, while area effects are prevalent for all homes within

\footnotetext{
${ }^{29}$ It is worth noting that these reference homes are situated in both rural and urban locales and therefore are not uniquely affected by influences from either setting. This further reinforces their worthiness as a reference category. Nonetheless, the question as to whether these homes are appropriate is addressed further in Models Three and Four.
} 
a 5-mile radius of the wind facility. Therefore, property value effects as identified by the coefficients of the variables inside of one mile (e.g., inside of 3000 feet/0.57 mile, and between 3000 feet/0.57 mile and 1 mile) can be interpreted as a combination of area and nuisance stigmas, while the coefficients of variables outside of one mile would be interpreted as only area sigma effects. All coefficients are expected to be negative and monotonically decreasing as the distance band increases.

\subsection{Model Three}

While Model Two relaxes some of the structural rigidity of Model One, it implicitly assumes that the area stigma effects die out completely after a distance of five miles from the wind facility. The validity of this assumption can be tested by comparing the prices of homes sold before the construction of the wind facility to those sold after. Further, by using only the post-construction data, both Models One and Two ignore the anticipated effect of wind facility construction by not using data from the post-announcement pre-construction period. Previous research suggests that property value effects might be very strong during this period, during which an assessment of actual impacts is not possible and buyers and sellers may take a risk-adverse and conservative stance (Wolsink, 1989). Model Three addresses both these issues by using the entire dataset, including homes that sold well before the facility was announced, through the period after announcement yet prior to construction, and continuing to well after construction. The following specification is used:

$$
\begin{aligned}
\ln (\mathrm{P})= & \beta_{0}+\beta_{1} \mathrm{~N}+\sum_{\mathrm{s}} \beta_{2} \mathrm{~S}+\sum_{\mathrm{k}} \beta_{3} \mathrm{X}+\sum_{\mathrm{v}} \beta_{4} \mathrm{VIEW} \cdot \mathrm{POSTCON} \\
& +\sum_{\mathrm{d}} \beta_{5} \mathrm{DISTANCE} \cdot \mathrm{POSTANC}+\varepsilon
\end{aligned}
$$


where POSTCON is one if the sale occurred after the wind facility was constructed (zero otherwise), POSTANC is one if the sale occurred after the wind facility was announced (zero otherwise), and all other variables are as defined in equation (2). Therefore, all pre-construction sales serve as the reference category for VIEW, and all pre-announcement sales serve as the reference category for DISTANCE. ${ }^{30}$

In this model, the scenic vista stigma is expected to be captured via the variable VIEW*POSTCON, and the area and nuisance stigmas through the interaction variable DISTANCE*POSTANC. The coefficients of the VIEW and DISTANCE variables, as with previous models, are expected to be negative and monotonically ordered.

\subsection{Model Four}

Model Three allows all post-announcement sales to be potentially impacted by area and nuisance stigma, and therefore might be considered an improvement over Model Two, but it makes the assumption that the marginal effect of DISTANCE is constant across all time periods. As discussed previously, however, there is some evidence that property value impacts may be particularly strong after the announcement of a disamenity, but then may fade with time as the community adjusts to the presence of that disamenity (e.g., Wolsink, 1989). Model Four allows for an investigation of how different periods of the wind project development process affect estimates for the impact of DISTANCE on sales prices. The following specification is used:

\footnotetext{
${ }^{30}$ This model, therefore, also serves as a robustness check on the reference categories in Models Two and Three. By comparing the coefficients for the DISTANCE and VIEW variables from both models, a comparison is made, in essence between the reference categories and therefore their appropriateness for use.
} 


$$
\begin{aligned}
\ln (\mathrm{P})= & \beta_{0}+\beta_{1} \mathrm{~N}+\sum_{\mathrm{s}} \beta_{2} \mathrm{~S}+\sum_{\mathrm{k}} \beta_{3} \mathrm{X}+\sum_{\mathrm{v}} \beta_{4} \mathrm{VIEW} \cdot \mathrm{POSTCON} \\
& +\sum_{\mathrm{y}} \beta_{5}(\mathrm{DISTANCE} \cdot \mathrm{PERIOD})+\varepsilon
\end{aligned}
$$

where PERIOD is a vector of development periods. The PERIOD variable contains six categories: (1) more than two years before announcement; (2) less than two years before announcement; (3) after announcement but before construction; (4) less than two years after construction; (5) between two and four years after construction; and (6) more than four years after construction.

In contrast to Models Two and Three, Model Four collapses the two DISTANCE categories inside of one mile into a single "less than one mile" group to ensure that reasonably large numbers of transactions (e.g., > 30) were used to estimate effects in each PERIOD (see Table 7 above). ${ }^{31}$ Therefore, in this model the DISTANCE variable contains four different levels: (1) less than one mile; (2) between one and three miles; (3) between three and five miles; and (4) outside of five miles.

The reference group in this model consists of transactions that occurred more than two years before the facility was announced for homes that were situated more than five miles from where the turbines were ultimately constructed. It is assumed that the value of these homes would not

\footnotetext{
${ }^{31}$ Although the results are not presented here, a specification where the two categories were not collapsed was estimated. The results from this alternative version do not differ from those presented here.
} 
be affected by the future presence of the wind facility. The VIEW parameters, although included in the model, are not interacted with PERIOD. ${ }^{32}$

Although the comparisons of these categorical variables between different DISTANCE and PERIOD categories might be interesting, it is the comparison of coefficients within each PERIOD and DISTANCE category that is the focus of this model. Such comparisons, for example, allow one to compare how the average value of homes inside of one mile that sold two years before announcement compare to the average value of homes inside of one mile that sold in the post-announcement-pre-construction period.

\section{Results}

The range of adjusted $\mathrm{R}^{2}$ values for the four models is between 0.75 and 0.77 (see Table 8 ). ${ }^{33}$ The sign and magnitudes of the controls are consistent with a priori expectations, are consistent across all four hedonic models, and all are statistically significant at the $1 \%$ level (see Table 9). ${ }^{34}$

\footnotetext{
32 The VIEW variable was considered most relevant for the post-construction period when turbines could actually be seen, so delineations based on development periods that extended into the pre-construction phase were unnecessary. It is conceivable, however, that VIEW effects vary in periods following construction, such as in the first two years or after that. Although this is an interesting question, the numbers of cases for the SUBSTANTIAL and EXTREME rankings - even if combined - when divided into the temporal periods were too small to be fruitful for analysis.

${ }^{33}$ All models were estimated with White's corrected standard errors (White, 1980) using the PROC REG procedure of SAS Version 9.2 TS1M0. It should also be noted that all Durbin-Watson (Durbin and Watson, 1951) test statistics were within the acceptable range of 1.89 and 2.53 (Gujarati, 2003), there was little multicollinearity associated with the variables of interest, and all results were robust to the removal of any cases with a Mahalanobis Distance statistic greater than 150 (Mahalanobis, 1936) and/or standardized residuals greater than four.

${ }^{34}$ To benchmark the results against those of other practitioners the research by Sirmans et al. (2005a; 2005b) was consulted. They conducted a meta-analysis of 64 hedonic studies carried out in multiple locations in the U.S. during
} 
The coefficients for spatial autocorrelation (Nbr_LN_SP96_hat_PC in Models One and Two, Nbr_LN_SP96_hat_All in Models Three and Four) are also significant above the 1\% level indicating a strong relationship between neighbors' selling prices and those of the subject home.

Of particular interest are the coefficient estimates for scenic vista (VISTA). Homes with a poor vista are found to sell for $21 \%$ to $25 \%$ less on average than homes with an average rating, while homes with a premium vista sell for $9 \%$ to $13 \%$ more than homes with an average rating. In all four of the models, differences between homes with an average scenic vista and homes with other scenic vistas are significant at the $1 \%$ level. Based on these results, it is evident that the quality of the scenic vista is capitalized into sales prices. ${ }^{35}$ The discussion following, focuses on what the results show as regards the three potential stigmas surrounding wind facilities.

multiple time periods, and investigated the coefficients of ten commonly used characteristics, seven of which were included in the model. The similarities between their mean coefficients (i.e., the average across all 64 studies) and those estimated in the present Models are striking. In the analysis presented here, the effect of square feet (in 1000s) on log of sales price was estimated to be 0.28 and Sirmans et al. provide an estimate of 0.34, while ACRES was similarly estimated (0.02 to 0.03, present Models and Sirmans et al., respectively). Further, AGEATSALE (age at the time of sale) (-0.006 to -0.009), BATHROOMS (0.09 to 0.09), CENTRALAC (0.09 to 0.08), and FIREPLACE (0.11 to 0.09) all similarly compare. As a group, the present Models' estimates differ from Sirmans et al. estimates in all cases by no more than a third of the Sirmans et al. mean estimate's standard deviation.

35 To benchmark these results, they were compared to the few studies that have investigated the contribution of inland scenic vistas to sales prices. Benson et al. (2000) found that a mountain vista increases sales price by $8 \%$, while Bourassa et al. (2004) found that wide inland vistas increase sales price by 7.6\%. These both compare favorably to the $10 \%$ and $14 \%$ above average and premium rated VISTA estimates. Comparable studies for below average and poor VISTA were not found and therefore no benchmarking of those coefficients was conducted. 
Table 8: Summary of Results

\begin{tabular}{|l|c|c|c|c|}
\cline { 2 - 5 } \multicolumn{1}{c|}{} & Model 1 & Model 2 & Model 3 & Model 4 \\
\hline Number of Cases & 4,937 & 4,937 & 7,459 & 7,459 \\
\hline Number of Predictors & 35 & 37 & 39 & 56 \\
\hline F Statistic & 468 & 443 & 580 & 404 \\
\hline Adjusted R2 & 0.77 & 0.77 & 0.75 & 0.75 \\
\hline
\end{tabular}

Table 9: Control Variable Results

\begin{tabular}{|c|c|c|c|c|}
\hline & Model 1 & Model 2 & Model 3 & Model 4 \\
\hline Intercept & $7.63(0.18)^{* * *}$ & $7.62(0.18)^{* * *}$ & $9.08(0.14)^{* * *}$ & $9.11(0.14)^{* * *}$ \\
\hline Nbr_LN_SP96_hat_PC & $0.29(0.02)^{* * *}$ & $0.29(0.02)^{* * *}$ & & \\
\hline Nbr_LN_SP96_hat_All & & & $0.16(0.01)^{* * *}$ & $0.16(0.01)^{* * *}$ \\
\hline AgeatSale & $-0.0059(0.00)^{* * *}$ & $-0.0059(0.00)^{* * *}$ & $-0.007(0.00)^{* * *}$ & $-0.007(0.00)^{* * *}$ \\
\hline AgeatSale_Sqrd & $0.00002(0.00)^{* * *}$ & $0.00002(0.00)^{* * *}$ & $0.00003(0.00)^{* * *}$ & $0.00003(0.00)^{* * *}$ \\
\hline Sqft_1000 & $0.28(0.01)^{* * *}$ & $0.28(0.01)^{* * *}$ & $0.28(0.01)^{* * *}$ & $0.28(0.01)^{* * *}$ \\
\hline Acres & $0.02(0.00)^{* * *}$ & $0.02(0.00)^{* * *}$ & $0.02(0.00)^{* * *}$ & $0.02(0.00)^{* * *}$ \\
\hline Baths & $0.09(0.01)^{* * *}$ & $0.09(0.01)^{* * *}$ & $0.08(0.01)^{* * *}$ & $0.08(0.01)^{* * *}$ \\
\hline ExtWalls_Stone & $0.21(0.02)^{* * *}$ & $0.21(0.02)^{* * *}$ & $0.21(0.01)^{* * *}$ & $0.21(0.01)^{* * *}$ \\
\hline CentralAC & $0.09(0.01)^{* * *}$ & $0.09(0.01)^{* * *}$ & $0.12(0.01)^{* * *}$ & $0.12(0.01)^{* * *}$ \\
\hline Fireplace & $0.11(0.01)^{* * *}$ & $0.11(0.01)^{* * *}$ & $0.11(0.01)^{* * *}$ & $0.12(0.01)^{* * *}$ \\
\hline FinBsmt & $0.08(0.02)^{* * *}$ & $0.08(0.02)^{* * *}$ & $0.09(0.01)^{* * *}$ & $0.09(0.01)^{* * *}$ \\
\hline Cul_De_Sac & $0.10(0.01)^{* * *}$ & $0.10(0.01)^{* * *}$ & $0.09(0.01)^{* * *}$ & $0.09(0.01)^{* * *}$ \\
\hline Water_Front & $0.34(0.04)^{* * *}$ & $0.33(0.04)^{* * *}$ & $0.35(0.03)^{* * *}$ & $0.35(0.03)^{* * *}$ \\
\hline Cnd_Low & $-0.44(0.05)^{* * *}$ & $-0.45(0.05)^{* * *}$ & $-0.43(0.04)^{* * *}$ & $-0.43(0.04)^{* * *}$ \\
\hline Cnd_BAvg & $-0.24(0.02)^{* * *}$ & $-0.24(0.02)^{* * *}$ & $-0.21(0.02)^{* * *}$ & $-0.21(0.02)^{* * *}$ \\
\hline Cnd_AAvg & $0.13(0.01)^{* * *}$ & $0.14(0.01)^{* * *}$ & $0.13(0.01)^{* * *}$ & $0.13(0.01)^{* * *}$ \\
\hline Cnd_High & $0.23(0.02)^{* * *}$ & $0.23(0.02)^{* * *}$ & $0.22(0.02)^{* * *}$ & $0.22(0.02)^{* * *}$ \\
\hline Vista_Poor & $-0.21(0.02)^{* * *}$ & $-0.21(0.02)^{* * *}$ & $-0.25(0.02)^{* * *}$ & $-0.25(0.02)^{* * *}$ \\
\hline Vista_BAvg & $-0.08(0.01)^{* * *}$ & $-0.08(0.01)^{* * *}$ & $-0.09(0.01)^{* * *}$ & $-0.09(0.01)^{* * *}$ \\
\hline Vista_AAvg & $0.10(0.02)^{* * *}$ & $0.10(0.02)^{* * *}$ & $0.10(0.01)^{* * *}$ & $0.10(0.01)^{* * *}$ \\
\hline Vista_Prem & $0.13(0.04)^{* * *}$ & $0.13(0.04)^{* * *}$ & $0.09(0.03)^{* * *}$ & $0.09(0.03)^{* * *}$ \\
\hline TXHC & $-0.75(0.03)^{* * *}$ & $-0.75(0.03)^{* * *}$ & $-0.82(0.02)^{* * *}$ & $-0.82(0.02)^{* * *}$ \\
\hline OKCC & $-0.44(0.02)^{* * *}$ & $-0.44(0.02)^{* * *}$ & $-0.53(0.02)^{* * *}$ & $-0.52(0.02)^{* * *}$ \\
\hline IABV & $-0.24(0.02)^{* * *}$ & $-0.24(0.02)^{* * *}$ & $-0.31(0.02)^{* * *}$ & $-0.30(0.02)^{* * *}$ \\
\hline ILLC & $-0.09(0.03)^{* * *}$ & $-0.09(0.03)^{* * *}$ & $-0.05(0.02)^{* *}$ & $-0.04(0.02)^{* *}$ \\
\hline WIKCDC & $-0.14(0.02)^{* * *}$ & $-0.14(0.02)^{* * *}$ & $-0.17(0.01)^{* * *}$ & $-0.17(0.02)^{* * *}$ \\
\hline PASC & $-0.30(0.03)^{* * *}$ & $-0.31(0.03)^{* * *}$ & $-0.37(0.03)^{* * *}$ & $-0.37(0.03)^{* * *}$ \\
\hline PAWC & $-0.07(0.03)^{* * *}$ & $-0.07(0.03)^{* * *}$ & $-0.15(0.02)^{* * *}$ & $-0.14(0.02)^{* * *}$ \\
\hline NYMCOC & $-0.20(0.03)^{* * *}$ & $-0.20(0.03)^{* * *}$ & $-0.25(0.02)^{* * *}$ & $-0.25(0.02)^{* * *}$ \\
\hline NYMC & $-0.14(0.02)^{* * *}$ & $-0.15(0.02)^{* * *}$ & $-0.15(0.02)^{* * *}$ & $-0.15(0.02)^{* * *}$ \\
\hline
\end{tabular}

Significant at or above the: $* * * 1 \%$ level, $* * 5 \%$ level, or $* 10 \%$ level. Standard Errors shown in parenthesis. 
Table 10: Variable of Interest Results

\begin{tabular}{|c|c|c|c|c|c|}
\hline \multirow{2}{*}{\multicolumn{2}{|c|}{ No View }} & Model 1 & Model 2 & Model 3 & Model 4 \\
\hline & & & & $0.02(0.01)^{*}$ & \\
\hline \multicolumn{2}{|c|}{ Minor View } & $-0.01(0.01)$ & $-0.01(0.01)$ & $0.00(0.02)$ & $-0.02(0.01)$ \\
\hline \multicolumn{2}{|c|}{ Moderate View } & $0.01(0.03)$ & $0.02(0.03)$ & $0.03(0.03)$ & $0.00(0.03)$ \\
\hline \multicolumn{2}{|c|}{ Substantial View } & $-0.01(0.07)$ & $-0.01(0.07)$ & $0.03(0.07)$ & $0.01(0.07)$ \\
\hline \multicolumn{2}{|c|}{ Extreme View } & $0.04(0.10)$ & $0.02(0.09)$ & $0.06(0.08)$ & $0.04(0.07)$ \\
\hline \multicolumn{2}{|c|}{ Inside 3000 Feet } & & $-0.05(0.06)$ & $-0.06(0.05)$ & \\
\hline \multicolumn{2}{|c|}{ Between 3000 Feet and 1 Mile } & & $-0.05(0.05)$ & $-0.08(0.05)^{*}$ & \\
\hline \multicolumn{2}{|c|}{ Between 1 and 3 Miles } & & $0.00(0.02)$ & $0.00(0.01)$ & \\
\hline \multicolumn{2}{|c|}{ Between 3 and 5 Miles } & & $0.02(0.01)$ & $0.01(0.01)$ & \\
\hline \multicolumn{2}{|c|}{ Outside 5 Miles } & & & $0.00(0.02)$ & \\
\hline \multicolumn{2}{|c|}{ DISTANCE } & $0.004(0.00)$ & & & \\
\hline \multicolumn{2}{|c|}{ DISTANCE*LT1MILE } & $0.086(0.11)$ & & & \\
\hline \multirow{6}{*}{$\begin{array}{c}\text { Inside } 1 \\
\text { Mile }\end{array}$} & Gtr2Yr_PreAnc & & & & $-0.13(0.06)^{* *}$ \\
\hline & \begin{tabular}{|l|} 
Lt2Yr_PreAnc \\
\end{tabular} & & & & $-0.10(0.05)^{*}$ \\
\hline & \begin{tabular}{|l|} 
PostAnc_PreCon \\
\end{tabular} & & & & $-0.14(0.06)^{* *}$ \\
\hline & Lt2Yr_PostCon & & & & $-0.09(0.07)$ \\
\hline & Btw2_4Yr_PostCon & & & & $-0.01(0.06)$ \\
\hline & Gtr4Yr_PostCon & & & & $-0.07(0.08)$ \\
\hline \multirow{6}{*}{$\begin{array}{l}\text { Between } \\
\text { 1-3 Miles }\end{array}$} & Gtr2Yr_PreAnc & & & & $-0.04(0.03)$ \\
\hline & Lt2Yr_PreAnc & & & & $0.00(0.03)$ \\
\hline & PostAnc_PreCon & & & & $-0.02(0.03)$ \\
\hline & Lt2Yr_PostCon & & & & $0.00(0.03)$ \\
\hline & Btw2_4Yr_PostCon & & & & $0.01(0.03)$ \\
\hline & Gtr4Yr_PostCon & & & & $0.00(0.03)$ \\
\hline \multirow{6}{*}{$\begin{array}{l}\text { Between } \\
\text { 3-5 Miles }\end{array}$} & Gtr2Yr_PreAnc & & & & $0.00(0.04)$ \\
\hline & Lt2Yr_PreAnc & & & & $0.00(0.03)$ \\
\hline & \begin{tabular}{|l|} 
PostAnc_PreCon \\
\end{tabular} & & & & $0.00(0.03)$ \\
\hline & Lt2Yr_PostCon & & & & $0.02(0.03)$ \\
\hline & Btw2_4Yr_PostCon & & & & $0.01(0.03)$ \\
\hline & Gtr4Yr_PostCon & & & & $0.01(0.03)$ \\
\hline \multirow{6}{*}{$\begin{array}{l}\text { Outside } \\
5 \text { Miles }\end{array}$} & Gtr2Yr_PreAnc & & & & \\
\hline & Lt2Yr_PreAnc & & & & $-0.03(0.04)$ \\
\hline & PostAnc_PreCon & & & & $-0.03(0.03)$ \\
\hline & Lt2Yr_PostCon & & & & $-0.03(0.03)$ \\
\hline & Btw2_4Yr_PostCon & & & & $0.03(0.03)$ \\
\hline & Gtr4Yr_PostCon & & & & $0.01(0.03)$ \\
\hline
\end{tabular}

Significant at or above the: $* * * 1 \%$ level, $* * 5 \%$ level, or $* 10 \%$ level. Standard Errors shown in parenthesis. 


\subsection{Area Stigma}

Area stigma is defined as a concern that the general area surrounding a wind energy facility will appear more developed, which may adversely affect home values in the local community regardless of whether any individual home has a view of the wind turbines. Though these impacts might be expected to be especially severe at close range to the turbines, the impacts could conceivably extend for a number of miles around a wind facility. Modern wind turbines are visible from well outside of five miles in many cases, so if an area stigma exists, it is possible that all of the homes in the study areas inside of five miles would be affected.

This hypothesis was tested in each of the four models (see Table 10). Model One used a continuous linear distance function and finds a relatively small (0.004) and non-significant ( $p$ value 0.25 ) relationship between distance (in miles) from the nearest turbine and the value of residential properties for the 4,937 transactions occurring after construction commenced on the turbines. ${ }^{36}$ Similarly, Model Two finds no statistical difference between the sales prices of homes located more than five miles from the turbines and those located between one and three miles from the turbines $(0.00, p$ value 0.80$)$ or between three and five miles $(0.02, p$ value 0.25$)$. Likewise, in Model Three, the coefficients of DISTANCE for homes that sold outside of one mile after construction are essentially no different to those that sold prior to construction with coefficients ranging between 0.00 and 0.01 , none of which are statistically significant. ${ }^{37}$ Further,

\footnotetext{
${ }^{36}$ As mentioned above, a number of alternative forms of the continuous distance function were also explored. In all cases the resulting continuous distance function was not statistically significant.

${ }^{37}$ It should also be noted that the stability of the DISTANCE coefficients across Models Two and Three, where different reference cases are used, reinforces both the stability of the models in general, and the appropriateness of the reference case selection.
} 
homes with No View - homes that would otherwise be unaffected - are found to appreciate in value, after adjusting for inflation, when compared to homes that sold before wind facility construction (0.02, $p$ value 0.06$)$; an area stigma effect should be reflected as a negative coefficient for this parameter.

Perhaps a more direct test of area stigma comes from the Model Four. In this model, homes in all distance bands outside of one mile and that sold after wind facility announcement are found to sell, on average, for prices that are not statistically different from sales that occurred more than two years prior to wind facility announcement.

In sum, there is little evidence of the existence of an area stigma among the homes in this sample. On average, homes in these study areas are not demonstrably and measurably stigmatized by the arrival of a wind facility based on area stigma, regardless of when they sold in the wind project development process and regardless of whether those homes are located one mile or five miles away from the nearest wind facility.

Drawing from the previous literature on environmental disamenities, one likely explanation for this result is that any adverse effects may fade rapidly beyond a short distance (such as a mile or two) from the wind facilities. For example, property value effects near a chemical plant have been found to fade outside of two and a half miles (Carroll et al., 1996), near a lead smelter (Dale et al., 1999) and fossil fuel plants (Davis, 2008) outside of two miles, and near landfills and confined animal feeding operations outside of 2,400 feet and 1,600 feet, respectively (Ready and Abdalla, 2005). Further, homes outside of 300 feet (Hamilton and Schwann, 1995) or even as 
little as 150 feet (Des-Rosiers, 2002) from a high voltage transmission line have been found to be unaffected.

\subsection{Scenic Vista Stigma}

Scenic vista stigma is defined as a concern that a home may be devalued because of the view of a wind energy facility, and the potential impact of that view on an otherwise scenic vista. It is premised on the notion that home values are, in part, derived from the quality of what can be viewed from the property.

As mentioned earlier, the results from all four models demonstrate persuasively that the quality of the scenic vista (the VISTA variable) does impact sales prices. Along the same lines, homes in the sample with water frontage or situated on a cul-de-sac sell for 33\% to 35\% more and $9 \%$ to $10 \%$ more, on average, respectively, than those homes that lack these characteristics, differences that are significant at or above the $1 \%$ level. Taken together, these results demonstrate that home buyers and sellers consistently take into account what can be seen from the home when sales prices are established, and that the models presented in this paper are able to clearly identify those impacts. $^{38}$

Despite this finding, the models are unable to identify any evidence of a scenic vista stigma associated with the wind facilities (see Table 10). Specifically, the 25 homes with EXTREME views in the sample, where the home site is "unmistakably dominated by the [visual] presence of

\footnotetext{
${ }^{38}$ Of course, cul-de-sacs and water frontage bestow other benefits to the home owner beyond the quality of the scenic vista, such as safety and privacy in the case of a cul-de-sac, and recreational potential and privacy in the case of water frontage.
} 
the turbines," are not found to have statistically different selling prices than either those that sold in the same period but which did not have a view (Models One and Two) or that sold prior to the wind facility's construction (Models Three and Four). The same finding holds for the 106 and 561 homes that were rated as having either MODERATE or MINOR views of the wind turbines, respectively.

It is hypothesized that although turbines are visible, and sometimes dramatically, that home buyers adjust to their visual presence, and therefore, do not discount the sale prices. in other words, self-selecting buyers without prejudice to the turbines, might be bidding on the properties, while others potential buyers who posses prejudice are not bidding. Of course, without further research, this theory cannot be confirmed.

\subsection{Nuisance Stigma}

We define nuisance stigma as any adverse impacts, such as sound and shadow flicker, that might uniquely affect residents of homes in close proximity to wind turbines, thereby leading to a potential reduction of home sales prices.

The results of Model One, where a continuous linear function is estimated for only those homes within one mile, imply a $4.1 \%$ reduction in the values of homes located one half mile away from the facility, and a $6.4 \%$ reduction for those within one quarter of a mile, but neither of these is statistically significant. $^{39}$ Similarly, Model Two finds that those homes within 3000 feet and those between 3000 feet and one mile of the nearest wind turbine sold for roughly $5 \%$ less than

\footnotetext{
${ }^{39}$ Effects for homes within a mile are calculated as follows: DISTANCE*0.004 + 0.086 - (DISTANCE*0.086).
} 
similar homes located more than five miles away that sold in the same post-construction period. Again, these differences are not statistically significant ( $p$-values 0.40 and 0.30 , respectively). In Model Three, when all transactions occurring after wind facility announcement are assumed to potentially be impacted, and a comparison is made to the average of all transactions occurring pre-announcement, the adverse impacts are estimated to be $-6 \%$ ( $p$ value 0.23 ) and $-8 \%$ ( $p$ value 0.08) respectively. Even though only one of these coefficients from the three models is statistically significant, they are large enough to warrant further scrutiny.

Model Four provides a clearer picture of these findings (see Figure 2). It is estimated that homes that sold prior to wind facility announcement but situated within one mile of the eventual location of the turbines sold, on average, for between $10 \%$ and $13 \%$ less than homes that sold in the same time period but located more than five miles away. Therefore, the homes nearest the wind facility’s eventual location were depressed in value, in comparison to homes further away, prior to the announcement of the facility. Moreover, comparing the sales prices of the homes located within a mile of the turbines between those that transacted more than two years prior to the facilities' announcement and those that sold in later periods (e.g., after announcement or after construction), as is shown in Table 11, differences were either statistically undistinguishable from, or in some cases greater than, pre-announcement levels. In other words, relative prices did not fall after the announcement and eventual construction of the wind facility for this sample of homes. 
Figure 2: Results from Model Four

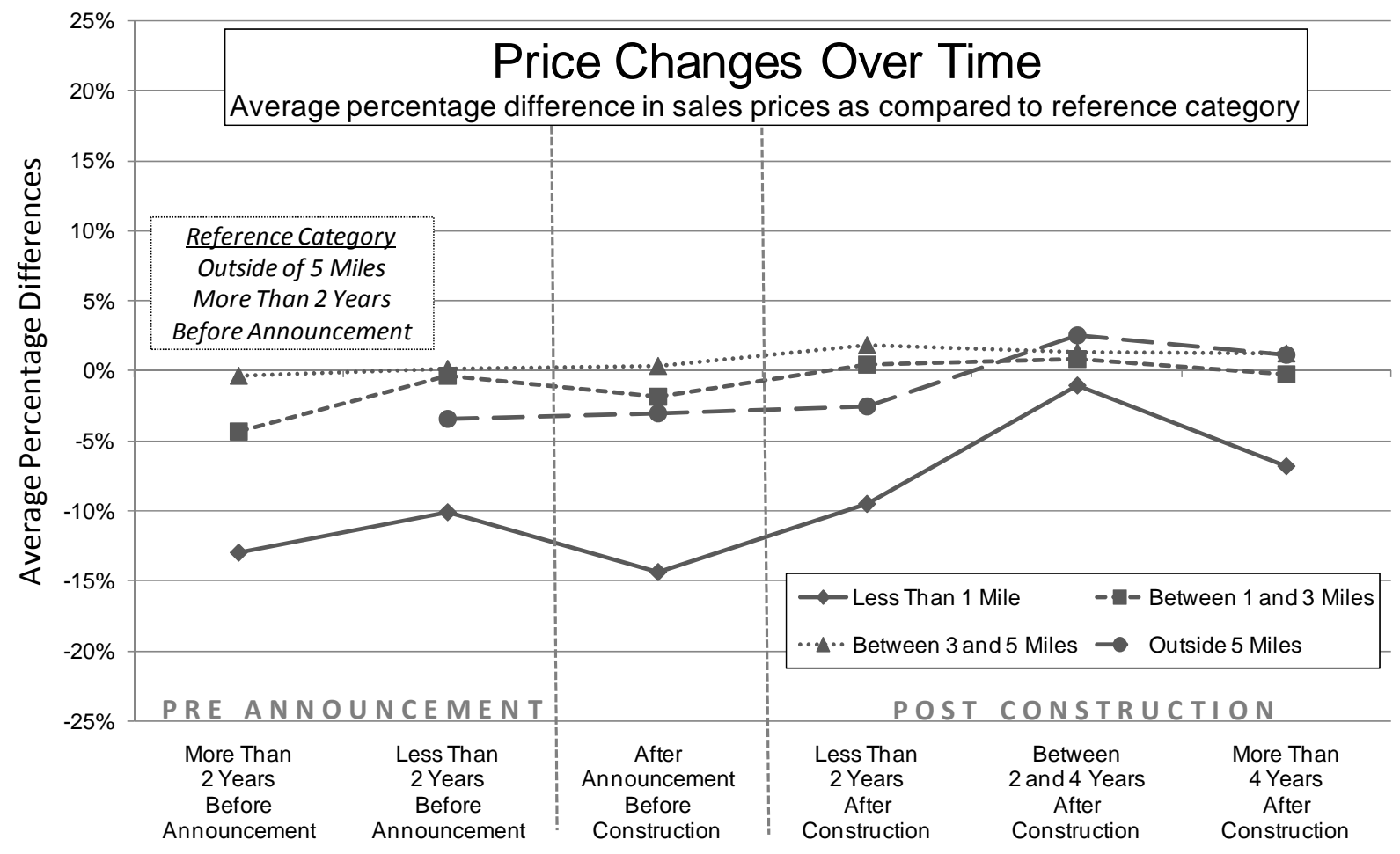

The reference category consists of transactions of homes situated more than five miles from where the nearest turbine would eventually be located and that occurred more than two years before announcement of the facility

\section{Table 11: Results from Equality Test of Model Four Coefficients}

\begin{tabular}{|l|c|c|c|c|c|c|}
\cline { 2 - 7 } \multicolumn{1}{c|}{} & $\begin{array}{c}\text { More Than } \\
\text { 2 Years } \\
\text { Before } \\
\text { Announcement }\end{array}$ & $\begin{array}{c}\text { Less Than } \\
\text { 2 Years } \\
\text { Before } \\
\text { Announcement }\end{array}$ & $\begin{array}{c}\text { After } \\
\text { Announcement } \\
\text { Before } \\
\text { Construction }\end{array}$ & $\begin{array}{c}\text { Less Than } \\
\text { 2 Years } \\
\text { After } \\
\text { Construction }\end{array}$ & $\begin{array}{c}\text { Between } \\
\text { 2 and } 4 \text { Years } \\
\text { After } \\
\text { Construction }\end{array}$ & $\begin{array}{c}\text { More Than } \\
\text { 4 Years } \\
\text { After } \\
\text { Construction }\end{array}$ \\
\hline Less Than 1 Mile & Reference & $0.03(0.45)$ & $-0.01(-0.13)$ & $0.04(0.56)$ & $0.12(1.74)^{*}$ & $0.06(0.88)$ \\
\hline Between 1 and 3 Miles & Reference & $0.04(1.92) *$ & $0.02(0.86)$ & $0.05(2.47) * *$ & $0.05(2.27)^{* *}$ & $0.04(1.82)^{*}$ \\
\hline Between 3 and 5 Miles & Reference & $0.01(0.37)$ & $0.01(0.34)$ & $0.02(0.77)$ & $0.02(0.78)$ & $0.02(0.79)$ \\
\hline Outside of 5 Miles $\dagger$ & Reference & $-0.04(-0.86)$ & $-0.03(-0.91)$ & $-0.03(-0.77)$ & $0.03(0.81)$ & $0.01(0.36)$ \\
\hline
\end{tabular}

Numbers represent the differences between coefficients in the target temporal category and those in the reference temporal category (more than 2 years before announcement) for the same distance band.

Numbers in parenthesis are $t$-Test statistics. Significance $=* * * 1 \%$ level, ** 5\% level, * $10 \%$ level, $<$ blank $>$ below the $10 \%$ level.

$\dagger$ For homes outside of 5 miles, the coefficient differences are equal to the coefficients in the Temporal Aspects Model, and therefore the tvalues were produced via the OLS.

The statistically insignificant differences found in Models One and Two, and the statistically significant result found in Model Three (for homes between 3000 feet and one mile), therefore 
appear to be a reflection of depressed home prices that preceded the construction of the relevant wind facilities. If construction of the wind facilities were downwardly influencing the sales prices of these homes, as might be deduced from Models One, Two, or Three alone, a diminution in the inflation adjusted price would be seen as compared to pre-announcement levels. Instead, an increase is seen. As such, no persuasive evidence of a nuisance stigma is evident in the data.

This argument notwithstanding, the results for Model Four need to be qualified in two ways. First, because the dataset contains few observations for homes located within one mile and that either sold more than two years before announcement or more than four years after construction, there is less confidence in these two coefficient estimates (-13\% and $-7 \%$ respectively) than for the estimates for other temporal periods inside of one mile. Based on additional sensitivity analysis not detailed here, it is believed that if these coefficients are biased, both are likely biased downward. $^{40}$ Second, the date of announcement of a project may be an imperfect indicator of a

\footnotetext{
${ }^{40}$ The subsets of data prior to the wind facilities announcement located inside of one mile are dominated by transactions from a single subdivision in one study area (OKCC). Local authorities contend that the subdivision, having been built (following WWII) away from the central business district among farm land and no other amenities, has been depressed in price, relative to similar homes located elsewhere in the community, well before the existence of the wind facility. Because no other variables in the model accounted for this stigma, and these homes dominated these subsets of data, the DISTANCE*PERIOD estimates were strongly influenced. When a fixed effect for this subdivision was entered into the model the estimates for the Gtr2Yr_PreAnc and Lt2Yr_PreAnc increased by $11 \%$ and $3 \%$ respectively, and no other estimates were noticeably influenced. Similarly, for the estimate more than four years following construction, two transactions, which otherwise appeared normal (and were located further from the turbines than others in the same study area) strongly influenced the parameter estimates downward by $\sim 4 \%$. The other DISTANCE*PERIOD estimates are robust to the removal of single or small groups of transactions.
} 
community's awareness of the project, and hence a weak predictor of the impact on property values in the pre-construction phase. ${ }^{41}$

Taken together, these two issues might imply that the estimated curve shown in Figure 2 for "less than one mile” transactions, instead of having a flat and then increasing shape, may have a more of an inverse parabolic (e.g., "U”) shape in reality. This would imply that sales prices relative to "pre-announcement" levels were depressed in the period after awareness began of the facility but before construction commenced, and then, following construction, prices recovered to levels more similar to those prior to announcement (and awareness). These results would be consistent with previous studies (e.g., Wolsink, 1989; Devine-Wright, 2004) that find that community members are likely to take a risk averse stance during the post-announcement preconstruction period when the impact on property values is difficult to quantify. Further research on this issue is warranted, but that need does not invalidate the basic conclusion presented here: there is no statistical evidence of a widespread nuisance stigma in the post-construction period for the wind facilities and homes in the sample.

Though this conclusion may appear counterintuitive, it may simply be that property value impacts fade rapidly with distance, and that few of the homes in the sample are close enough to the subject wind facilities to be substantially impacted. As discussed earlier, studies of the property value impacts of high voltage transmission lines often find that effects fade towards zero at as little distance as 300 feet (see, e.g., Gallimore and Jayne, 1999; Watson, 2005). None

\footnotetext{
${ }^{41}$ As discussed in footnote 19 "awareness" of the project in the community may precede the "announcement date", and therefore transactions in the period "less than two years before announcement" could conceivably have been influenced by the prospective wind project.
} 
of the homes in the dataset is closer than 800 feet to the nearest wind turbine, and all but eight homes are located outside of 1000 feet of the nearest turbine. It is therefore possible that, if any effects do exist, they exist at very close range to the turbines, and that those effects are of small magnitude outside of 800 feet. Finally, effects that existed soon after the announcement or construction of the wind facilities might have faded over time as self selecting buyers who are not sensitive to the presence of the facility move into the area. More than half of the homes in the sample sold more than three years after the commencement of construction, and studies of transmission lines have found that effects fade over time (Kroll and Priestley, 1992), while studies of attitudes towards wind turbines have found that such attitudes often improve after facility construction (Wolsink, 1989). Regardless of the explanation, the fact remains that, in this sizable sample of residential transactions, no persuasive evidence of a nuisance stigma is found, and if these impacts do exist, they are either too small or too infrequent to result in any statistically observable impact among the sample. 


\section{Conclusions (Summary Statement)}

This paper has investigated the potential impacts of wind power facilities on the sales prices of residential properties that are in proximity to and/or that have a view of those wind facilities. In so doing, three different potential impacts of wind projects on property values have been identified and analyzed: area stigma, scenic vista stigma, and nuisance stigma. The results are based on the most comprehensive data on and analysis of the subject to date. Across various model specifications, no discernable statistical evidence of the presence of these stigmas is found. At least for the 24 wind facilities and 7,459 sales transactions included in the sample, no evidence of a widespread impact of wind facilities on residential sales prices is detected.

Nonetheless, a lack of evidence should not be construed as evidence of lacking. In other words, the analysis cannot dismiss the possibility that a small number of homes, especially those that are very close to wind facilities, might be negatively impacted, especially those transacting after announcement of the facility and prior to construction, when risks are difficult to quantify and therefore might be amplified. The data are not sufficiently large to be able to detect possible impacts within, for example, 1000 feet of the nearest turbine. As such, subsequent research should concentrate on homes located closest to wind facilities. With each passing year, and each additional installed wind facility, more data becomes available for additional analysis. Further, it is conceivable that cumulative impacts might exist whereby communities that have seen repetitive development are affected uniquely, and these cumulative effects may be worth investigating. Although the analysis finds no statistically significant effects on property values, it is unable to indicate why this is so. A particularly useful investigation would be a comparative attitudinal analysis of buyers and sellers. Such an analysis might be used to test the claim that the 
absence of adverse property values impact is explained by buyers moving into the area who are insensitive to the presence of a wind facility. Finally, future research might also analyze the possible impact of wind facilities on the amount of time it takes to sell a home, a factor that not considered in the present work. 


\section{References}

BBC Research \& Consulting (BBC R\&C) (2005) Wind Power Facility Siting Case Studies:

Community Response. BBC Research \& Consulting. Prepared for National Wind Coordinating Committee, c/o RESOLVE, Washington, DC. June, 2005. 51 pages.

Beck, D. (2004) How Hull Wind "I" Impacted Property Values in Pemberton. Letter sent to C. McCabe. July 28, 2004.

Benson, E. D., Hansen, J. L. and Aurthur L. Schwartz, J. (2000) Water Views and Residential Property Values. The Appraisal Journal. 68(3): 260-270.

Bishop, I. (2002) Determination of Thresholds of Visual Impact: The Case of Wind Turbines. Environment and Planning B: Planning and Design. 29: 707-718.

Bond, S. (2008) Attitudes Towards the Development of Wind Farms in Australia. Journal of Environmental Health Australia. 8(3): 19-32.

Bourassa, S. C., Hoesli, M. and Sun, J. (2004) What's in a View? Environment and Planning. 36(8): 1427-1450.

Buhyoff, G. J., Miller, P. A., Roach, J. W., Zhou, D. and Fuller, L. G. (1994) An AI Methodology for Landscape Visual Assessments. AI Applications. 8(1): 1-13.

Carroll, T. M., Clauretie, T. M., Jensen, J. and Waddoups, M. (1996) The Economic Impact of a Transient Hazard on Property Values: The 1988 PEPCON Explosion in Henderson, Nevada. Journal of Real Estate Finance and Economics. 13(2): 143-167.

Dale, L., Murdoch, J. C., Thayer, M. A. and Waddell, P. A. (1999) Do Property Values Rebound from Environmental Stigmas? Evidence from Dallas. Land Economics. 75(2): 311-326.

Daniel, T. C. and Boster, R. S. (1976) Measuring Landscape Aesthetics: The Scenic Beauty Estimation Method. Forest Service - Rocky Mountian Forest and Range Experiment 
Station in Fort Collins Colorado. Prepared for U.S. Department of Agriculture, Washington, D.C. 66 pages.

Davis, L. W. (2008) The Effect Of Power Plants On Local Housing Values And Rents: Evidence From Restricted Census Microdata. Prepared for Center for Energy and Environmental Policy Research (CEEPR), Cambridge, MA. June 18, 2008. 34 pages. 08-009.

DeLacy, B. (2005) Technical Memorandum: Impacts of The Kittitas Valley Wind Power Project on Local Property Values. Cushman \& Wakefield of Oregon. Prepared for Sagebrush Power Partners, LLC. December 29, 2005. 15 pages. File Number 06-34001-9012.

Des-Rosiers, F. (2002) Power Lines, Visual Encumbrance and House Values: A Microspatial Approach to Impact Measurement. Journal of Real Estate Research. 23(3): 275-301.

Devine-Wright, P. (2004) Beyond NIMBYism: Towards an Integrated Framework for Understanding Public Perceptions of Wind Energy. Wind Energy. 8(2): 125 - 139.

Durbin, J. and Watson, G. S. (1951) Testing for Serial Correlation in Least-Squares Regression. Biometrika. 38(1-2): 159-178.

Firestone, J. and Kempton, W. (2006) Public Opinion about Large Offshore Wind Power: Underlying Factors. Energy Policy. 35(3): 1584-1598.

Firestone, J., Kempton, W. and Krueger, A. (2007) Delaware Opinion on Offshore Wind Power Interim Report. University of Delaware College of Marine and Earth Studies, Newark, DE. January, 2007. 16 pages.

Gallimore, P. and Jayne, M. R. (1999) Public and Professional Perceptions of HVOTL Risks: The Problem of Circularity. Journal of Property Research. 16(3): 243-255. Cited by Elliott and Wadley, 2002. 
Gipe, P. (2002) Design as if People Matter: Aesthetic Guidelines for a Wind Power Future.

Section in Wind Power in View: Energy Landscapes in a Crowded World. Academic Press. Davis, CA. pp. 173-212 of 234 pages. ISBN 0-12-546334-0.

Global Wind Energy Council (GWEC) (2008) Global Wind Energy Outlook. Global Wind Energy Council, Brussels, Belgium, and Greenpeace, Amsterdam, The Netherlands. October, 2008. 60 pages.

Global Wind Energy Council (GWEC) (2009) Global Wind 2008 Report. Global Wind Energy Council, Brussels, Belgium, and Greenpeace, Amsterdam, The Netherlands. 60 pages.

Goldman, J. C. (2006) A Study in the Impact of Windmills on Property Values in Tucker County, West Virginia for the Proposed Beech Ridge Energy, L.L.C. project in Greenbrier County, West Virginia. Goldman Associates Inc. Prepared for Spilman Thomas \& Battle, P.L.L.C., Charleston, WV. April, 2006. 51 pages. West Virginia Case No. 05-1590-E-CS. Grover, D. S. (2002) Economic Impacts of Wind Power in Kittitas County, WA. ECONorthwest. Prepared for Phoenix Economic Development Group, Ellensburg, WA. November, 2002. 18 pages.

Gujarati, D. N. (2003) Basic Econometrics: Fourth Edition. McGraw-Hill/Irwin. New York, NY. 1002 pages. ISBN 0-07-233542-4.

Hamilton, S. and Schwann, G. (1995) Do High Voltage Electric Transmission Lines Affect Property Value? Land Economics. 71(4): 436-444.

Haughton, J., Giuffre, D., Barrett, J. and Tuerck, D. G. (2004) An Economic Analysis of a Wind Farm in Nantucket Sound. Beacon Hill Institute at Suffolk University, Boston, MA. May, 2004. 83 pages. 
Hoen, B. (2006) Impacts of Windfarm Visibility on Property Values in Madison County, New York. Thesis Prepared for Masters Degree in Environmental Policy. Bard College, Annandale-On-Hudson, NY. April, 2006. 73 pages.

Jerabek, J. (2001) Property Values and their Relationship to the Town of Lincoln's Wind Turbine Projects. Letter sent to R. Bingen. January 30, 2001.

Jerabek, J. (2002) Property Values Respective to Wind Turbine Locations. Letter sent to Township of Lincoln Wind Turbine Moratorium Study Committee. January 29, 2002. Jordal-Jorgensen, J. (1996) Visual Effect and Noise from Windmills - Quantifying and Valuation. Social Assessment of Wind Power in Denmark. J. Munksgaard and A. Larsen. Prepared for The Institute of Local Government Studies (AKF), Copenhagen, Denmark. April 1996.

Khatri, M. (2004) RICS Wind Farm Research: Impact of Wind Farms on the Value of Residential Property and Agricultural Land. Prepared for Royal Institute of Chartered Surveyors, London, UK. November 3, 2004. 11 pages.

Kielisch, K. (2009) Wind Turbine Impact Study: Dodge and Fond Du Lac Counties, WI. Appraisal Group One. Prepared for Calumet County Citizens for Responsible Energy (CCCRE), Calumet County, WI. September 9, 2009. 73 pages.

Kroll, C. A. and Priestley, T. (1992) The Effects of Overhead Transmission Lines on Property Values: A Review and Analysis of the Literature. Prepared for Edison Electric Institute, Washington, DC. July, 1992. 99 pages.

Mahalanobis, P. C. (1936) On the Generalized Distance in Statistics. Proceedings of the National Institute of Sciences of India. 2(1): 49-55. 
Malpezzi, S. (2003) Hedonic Pricing Models: A Selective and Applied Review. Section in Housing Economics and Public Policy: Essays in Honor of Duncan Maclennan. WileyBlackwell. Hoboken, NJ. pp. 67-85 of 328 pages. ISBN 978-0-632-06461-8.

McCann, M. S. (2008) Real Estate Impact Evaluation of the Horizon Wind Energy Proposed Rail Splitter Wind Farm. Prepared for Hinshaw \& Culbertson, LLP, Rockford, IL. May, 2008. 24 pages.

Pitt, D. G. and Zube, E. H. (1979). The Q-Sort Method: Use in Landscape Assessment Research and Landscape Planning. Presented at Applied Techniques for Analysis and Management of the Visual Resource, Incline Village, Nevada. April 23-25, 1979.

Poletti, P. (2005) A Real Estate Study of the Proposed Forward Wind Energy Center Dodge and Fond Du Lac Counties, Wisconsin. Poletti and Associates. Prepared for Invenergy Wind LLC, Chicago, IL. May, 2005. 106 pages.

Poletti, P. (2007) A Real Estate Study of the Proposed White Oak Wind Energy Center, Mclean \& Woodford Counties, Illinois. Polleti and Associates. Prepared for Invenergy Wind LLC, Chicago, IL. January, 2007. 63 pages.

Ready, R. C. and Abdalla, C. W. (2005) The Amenity and Disamenity Impacts of Agriculture: Estimates from a Hedonic Pricing Model. American Journal of Agricultural Economics. 87(2): 314-326.

Simons, R. A. and Saginor, J. D. (2006) A Meta-Analysis of the Effect of Environmental Contamination and Positive Amenities on Residential Real Estate Values. Journal of Real Estate Research. 28(1): 71-104.

Sims, S. and Dent, P. (2007) Property Stigma: Wind Farms Are Just The Latest Fashion. Journal of Property Investment \& Finance. 25(6): 626-651. 
Sims, S., Dent, P. and Oskrochi, G. R. (2008) Modeling the Impact of Wind Farms on House Prices in the UK. International Journal of Strategic Property Management. 12(4): 251269.

Sirmans, G. S., Lynn, M., Macpherson, D. A. and Zietz, E. N. (2005a). The Value of Housing Characteristics: A Meta Analysis. Presented at Mid Year Meeting of the American Real Estate and Urban Economics Association. May 2005.

Sirmans, G. S., Macpherson, D. A. and Zietz, E. N. (2005b) The Composition of Hedonic Pricing Models. Journal of Real Estate Literature. 13(1): 3-42.

Sterzinger, G., Beck, F. and Kostiuk, D. (2003) The Effect of Wind Development on Local Property Values. Renewable Energy Policy Project, Washington, DC. May, 2003. 77 pages.

Torres-Sibillea, A., V. Cloquell-Ballester and Darton, R. (2009) Development and Validation of a Multicriteria Indicator for the Assessment of Objective Aesthetic Impact of Wind Farms. Renewable and Sustainable Energy Reviews. 13(1): 40-66.

United States Department of Agriculture (USDA) (1995) Landscape Aesthetics: A Handbook for Scenic Management. United States Department of Agriculture - Forest Service, Washington, DC. December 1995.

United States Department of Energy (US DOE) (2008) 20\% Wind Energy by 2030: Increasing Wind Energy's Contribution to U.S. Electricity Supply. U.S. Department of Energy, Washington, DC. May, 2008. 248 pages.

Watson, M. (2005) Estimation of Social and Environmental Externalities for Electricity Infrastructure in the Northwest Sector. Reviewed by Martin Hill. Prepared for Prepared for Parsons Brinckerhoff by Integral Energy, Sydney, Australia. August 2005. 73 pages. 
White, H. (1980) A Heteroskedasticity-Consistent Covariance Matrix Estimator and a Direct Test for Heteroskedasticity. Econometrica. 48(4): 817-838.

Wiser, R. and Bolinger, M. (2009) 2008 Wind Technologies Market Report. Lawrence Berkeley National Laboratory. Prepared for U.S. Department of Energy, Washington, DC. July, 2009. 68 pages. DOE/GO-102009-2868.

Wiser, R. and Hand, M. (2010) Wind Power: How Much, How Soon, and At What Cost? Section in Generating Electricity in a Carbon-Constrained World. Elsevier. Oxford, UK. p. 632. ISBN-13: 978-1-85617-655-2.

Wolsink, M. (1989) Attitudes and Expectancies about Wind Turbines and Wind Farms. Wind Engineering. 13(4): 196-206.

Wolsink, M. (2000) Wind Power and the NIMBY-Myth: Institutional Capacity and the Limited Significance of Public Support. Renewable Energy. 21(1): 49-64. 